\title{
Comparative Measurements of Earth and Martian Entry Environments in the NASA Langley HYMETS Facility
}

\author{
Scott C. Splinter ${ }^{1}$, Kim S. Bey ${ }^{2}$, and Jeffrey G. Gragg ${ }^{3}$ \\ NASA Langley Research Center, Hampton, VA 23681 \\ Amy Brewer ${ }^{4}$ \\ Analytical Services and Materials Inc., Hampton, VA 23666
}

\begin{abstract}
Arc-jet facilities play a major role in the development of heat shield materials for entry vehicles because they are capable of producing representative high-enthalpy flow environments. Arc-jet test data is used to certify material performance for a particular mission and to validate or calibrate models of material response during atmospheric entry. Materials used on missions entering Earth's atmosphere are certified in an arc-jet using a simulated air entry environment. Materials used on missions entering the Martian atmosphere should be certified in an arc-jet using a simulated Martian atmosphere entry environment, which requires the use of carbon dioxide. Carbon dioxide has not been used as a test gas in a United States arc-jet facility since the early 1970's during the certification of materials for the Viking Missions. Materials certified for the Viking missions have been used on every entry mission to Mars since that time. The use of carbon dioxide as a test gas in an arc-jet is again of interest to the thermal protection system community for certification of new heat shield materials that can increase the landed mass capability for Mars bound missions beyond that of Viking and Pathfinder. This paper describes the modification, operation, and performance of the Hypersonic Materials Environmental Test System (HYMETS) arc-jet facility with carbon dioxide as a test gas. A basic comparison of heat fluxes, various bulk properties, and performance characteristics for various Earth and Martian entry environments in HYMETS is provided. The Earth and Martian entry environments consist of a standard Earth atmosphere, an oxygen-rich Earth atmosphere, and a simulated Martian atmosphere. Finally, a preliminary comparison of the HYMETS arc-jet facility to several European plasma facilities is made to place the HYMETS facility in a more global context of arc-jet testing capability.
\end{abstract}

\section{Nomenclature}

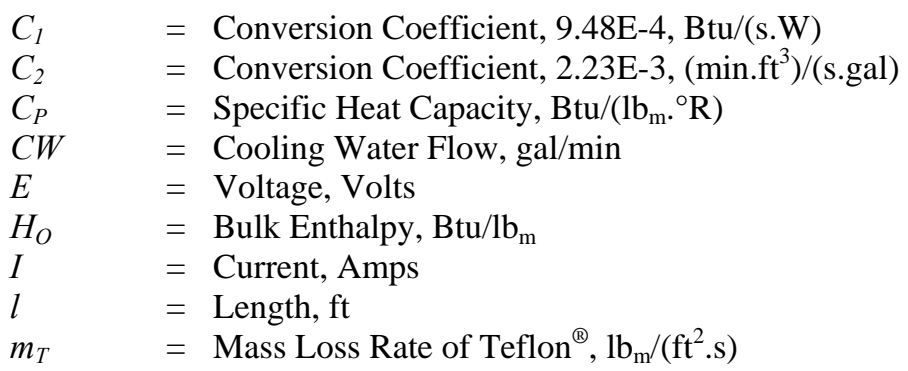

\footnotetext{
${ }^{1}$ Aerospace Engineer, Structural Mechanics and Concepts Branch, Mail Stop 190, AIAA Member

${ }^{2}$ Senior Researcher, Structural Mechanics and Concepts Branch, Mail Stop 190

${ }^{3}$ Engineering Technician, Structures Experiments Branch, Mail Stop 188D

${ }^{4}$ Senior Test Engineer, Analytical Services and Materials, Inc., Mail Stop 190
}

This material is declared a work of the U.S. Government and is not subject to copyright protection in the United States. 


\begin{tabular}{|c|c|}
\hline$M_{\text {Total }}$ & $=$ Mass Flow Rate, $\mathrm{lb}_{\mathrm{m}} / \mathrm{s}$ \\
\hline$P_{\text {stag }}$ & $=$ Stagnation Pressure, atm \\
\hline$q_{F C C W}$ & $=$ Fully-Catalytic Cold Wall Heat Flux Rate, Btu/(ft².s) \\
\hline$q_{N C C W}$ & $=$ Non-Catalytic Cold Wall Heat Flux Rate, Btu/(ft $\left.{ }^{2} . \mathrm{s}\right)$ \\
\hline$R_{e f f}$ & $=$ Effective Hemispherical Radius, $\mathrm{ft}$ \\
\hline$R_{\text {Flat Face }}$ & $=$ Flat Face Radius, $\mathrm{ft}$ \\
\hline$t$ & $=$ time, $\mathrm{s}$ \\
\hline$T$ & $=$ Temperature, ${ }^{\circ} \mathrm{R}$ \\
\hline$T_{C W}$ & $=$ Cooling Water Temperature, ${ }^{\circ} \mathrm{R}$ \\
\hline$T_{F C C W}$ & $=$ Fully-Catalytic Cold Wall Temperature, ${ }^{\circ} \mathrm{R}$ \\
\hline$\Delta$ & $=$ Change \\
\hline$\rho$ & $=$ Density, $\mathrm{lb}_{\mathrm{m}} / \mathrm{ft}^{3}$ \\
\hline
\end{tabular}

\section{Introduction}

rc-jet facilities play a major role in the development of heat shield materials for entry vehicles because they are capable of producing representative high-enthalpy flow environments. Arc-jet test data is used to certify material performance for a particular mission and to validate or calibrate models of material response during atmospheric entry. Extensive arc-jet testing was conducted during the development of the Superlight Ablator, known as SLA-561V, which was used on the forebody heat shield of every entry mission to Mars: Viking Landers 1 and 2 in 1976, Mars Pathfinder in 1997, Mars Polar Lander in 1999, Mars Exploration Rovers' Spirit and Opportunity in 2004, and Mars Phoenix Lander in 2008.

The arc-jet test database generated in the late 1960's and early 1970's on SLA-561V for the Viking Landers included tests in a standard Earth atmosphere consisting of 79\% Nitrogen $\left(\mathrm{N}_{2}\right)$ and $21 \%$ Oxygen $\left(\mathrm{O}_{2}\right)$ by volume (or equivalently moles) and two simulated Martian atmospheres: 1) $72 \% \mathrm{~N}_{2}$ and $28 \%$ Carbon Dioxide $\left(\mathrm{CO}_{2}\right)$ and 2) $50 \% \mathrm{~N}_{2}$ and $50 \% \mathrm{CO}_{2}$ by volume. ${ }^{1-3}$ The Viking database was expanded in the early 1990 's to include the higher entry heating environment for the Mars Pathfinder mission., ${ }^{4,5}$ Certification of SLA-561V for use on the Mars Pathfinder mission was performed using only a standard Earth atmosphere because $\mathrm{CO}_{2}$ test capability no longer existed in the United States. All subsequent Mars missions relied on the expanded database from which ablation response models were calibrated.

The Mars Science Laboratory (MSL), scheduled for launch in late 2011, represents a significant increase in size and landed mass over that of previous missions. The resulting increase in the entry heating environment again required the certification of SLA-561V for use on the forebody heat shield. During arc-jet certification, SLA-561V suffered a catastrophic failure at conditions within the flight envelope for MSL. The MSL program then selected Phenolic Impregnated Carbon Ablator, or PICA, for use on the forebody heatshield ${ }^{6,7}$ as it was successfully used for the Stardust return capsule and was one of two ablators being considered for the Orion Crew Exploration Vehicle (CEV). The CEV arc-jet database and response models for PICA were expanded to include the Martian atmospheric entry conditions predicted for MSL. To compensate for the fact that testing in $\mathrm{CO}_{2}$ could not be performed, response models for PICA were indirectly validated by varying the percentage of oxygen ${ }^{7}$ in arc-jet tests performed at the NASA Johnson Space Center (JSC). One of the differences between tests in air and $\mathrm{CO}_{2}$ is the amount of available oxygen and it is unknown whether an oxygen-rich environment is comparable to a $\mathrm{CO}_{2}$ environment.

Future robotic and manned missions to Mars with a significant increase in landed mass and a corresponding increase in entry heating will require the certification of heritage or new materials in relevant environments. Currently European ${ }^{8-11}$, Russian ${ }^{12}$, and Japanese ${ }^{13}$ facilities are performing significant research using $\mathrm{CO}_{2}$ as a test gas. NASA Langley Research Center's Hypersonic Materials Environmental Test System (HYMETS) facility was recently modified to provide a $\mathrm{CO}_{2}$ test environment, and to serve as a pilot facility for $\mathrm{CO}_{2}$ enhancements to the larger arc-jet facility at NASA Johnson Space Center. The purpose of this paper is to describe the modification, operation, and performance of the HYMETS arc-jet facility using $\mathrm{CO}_{2}$ as a test gas. A basic comparison of heat fluxes, bulk properties, and performance characteristics for various Earth and Martian entry environments in HYMETS is provided. The Earth and Martian entry environments consist of a standard Earth atmosphere, an oxygen-rich Earth atmosphere, and a simulated Martian atmosphere. Finally, a preliminary comparison of the HYMETS arc-jet facility to several European plasma facilities is made. 


\section{HYMETS Facility}

\section{A. Facility History}

The HYMETS facility was installed at NASA Langley Research Center in 1968 as a $100 \mathrm{~kW}$ segmentedconstrictor-direct-current-electric-arc-heated plasma wind tunnel. Throughout the 1970's, 80's, 90's, and early 2000's it was used primarily for emissivity, catalysity, and dynamic oxidation testing of metals and coatings for hypersonic vehicles. ${ }^{14-16}$ The range of test conditions for the HYMETS facility during that time is presented in Table 1. The facility was upgraded to $400 \mathrm{~kW}$ in 2005 expanding its range of test conditions to those presented in Table $2 .{ }^{17}$ Since then HYMETS has been used primarily for characterization of ceramic matrix composite (CMC) materials, rigid and flexible ablators, high-temperature coatings, and for performing research and development on plasma flow diagnostics.

Table 1. HYMETS Historic Test Conditions

\begin{tabular}{|l|c|}
\hline Specimen Surface Temperature $\left({ }^{\circ} \mathrm{F}\right)$ & $1472-2732$ \\
\hline Specimen Stagnation Pressure $(\mathrm{atm})$ & $0.004-0.008$ \\
\hline Free Stream Mach Number & 3.5 \\
\hline Free Stream Enthalpy $\left(\mathrm{Btu} / \mathrm{lb}_{\mathrm{m}}\right)$ & $1719-4730$ \\
\hline Cold Wall Heating Rate $\left(\mathrm{Btu} / \mathrm{ft}^{2} . \mathrm{s}\right)$ & $70-400$ \\
\hline
\end{tabular}

Table 2. HYMETS Current Test Conditions

\begin{tabular}{|l|c|}
\hline Specimen Surface Temperature $\left({ }^{\circ} \mathrm{F}\right)$ & $2300-4500$ \\
\hline Specimen Stagnation Pressure $(\mathrm{atm})$ & $0.013-0.079$ \\
\hline Free Stream Mach Number & 5.0 \\
\hline Free Stream Enthalpy $\left(\mathrm{Btu} / \mathrm{lb}_{\mathrm{m}}\right)$ & $2300-11500$ \\
\hline Cold Wall Heating Rate $\left(\mathrm{Btu} / \mathrm{ft}^{2} . \mathrm{s}\right)$ & $100-600$ \\
\hline
\end{tabular}

\section{B. Facility Configuration}

The HYMETS facility is shown in its entirety in Fig. 1. HYMETS is configured with a segmented-constrictordc-electric-arc-heater as an arc plasma generator. The arc plasma generator, schematic and photograph shown in Figs. 2 and 3 respectively, is mounted on the outside of the test chamber door. It consists of a copper cathode with tungsten button emitter, 32 electrically-isolated copper segment constrictors with a 0.5 -inch diameter bore, a copper divergent-ring anode, and a copper convergent-divergent Mach 5 nozzle. The nozzle has a 0.5-inch diameter throat, 2.5-inch diameter exit plane, and a half-angle of 8 degrees. All arc plasma generator components are water cooled with jackets or by internal passageways.

Test gasses are injected tangentially into the bore of the arc plasma generator at six discrete locations. The gasses are heated by a high-voltage electric arc that is maintained between the cathode and anode to create a high temperature ionized plasma flow. The electric arc is spin-stabilized in the arc plasma generator by the vortex motion of the injected test gasses. The test gasses used in the arc plasma generator are supplied by several compressed gas cylinders, shown in Fig. 4, and can be custom mixed to the desired atmosphere. Adjustable volume percentages of $\mathrm{N}_{2}$ and Argon (Ar) are used as shield gasses near the cathode and anode, respectively, to protect the electrodes from rapid oxidation. Power to the electrodes is provided by a $400 \mathrm{~kW}$ power supply with an induction filter shown in Fig. 5.

The plasma flow from the arc plasma generator is accelerated through the nozzle and exhausted into a 2-foot diameter by 3 -foot long vacuum test chamber where it stagnates on one of four water-cooled injection stings arranged symmetrically around the inside circumference of the test chamber. The flow is then captured by a collector cone with an 8-inch diameter inlet plane, a 6-inch diameter constant cross-section diffuser, and a coiledcopper tubing heat exchanger to decelerate and cool the flow. A two-stage, continuous-flow, high-mass-capacity, mechanical pumping system, shown in Fig. 6, is used to evacuate the plasma flow from the facility. The collector, diffuser, heat exchanger, and mechanical pumping system provide for expansion of the plasma flow from the nozzle. The facility is cooled by a 150 ton re-circulating chiller with associated booster pumps and heat exchangers.

The HYMETS facility is computer-controlled by commercially available software ${ }^{18}$ from a PC workstation and a Programmable Logic Control (PLC) touch-screen module shown in Fig. 7. Test conditions are controlled by adjusting the current and test gas mass flow rate setpoints for the arc plasma generator, which can be operated either 
manually or automatically allowing for the generation of test profiles. Test specimens and instrumentation probes are mounted on the four injection stings which are inserted into the plasma flow by the PLC touch-screen module.

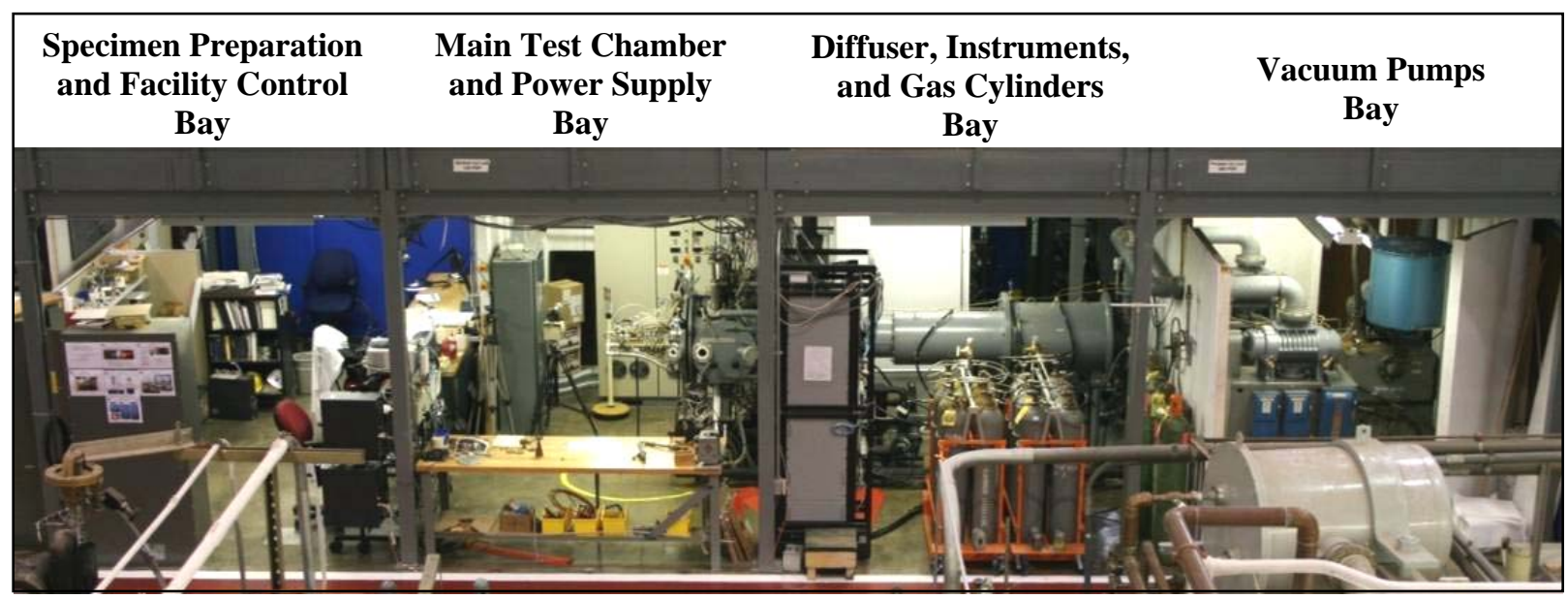

Figure 1. HYMETS Facility

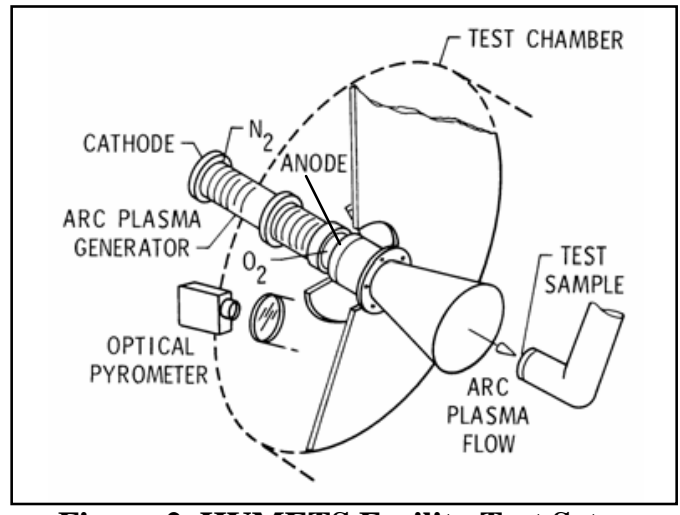

Figure 2. HYMETS Facility Test Setup Schematic

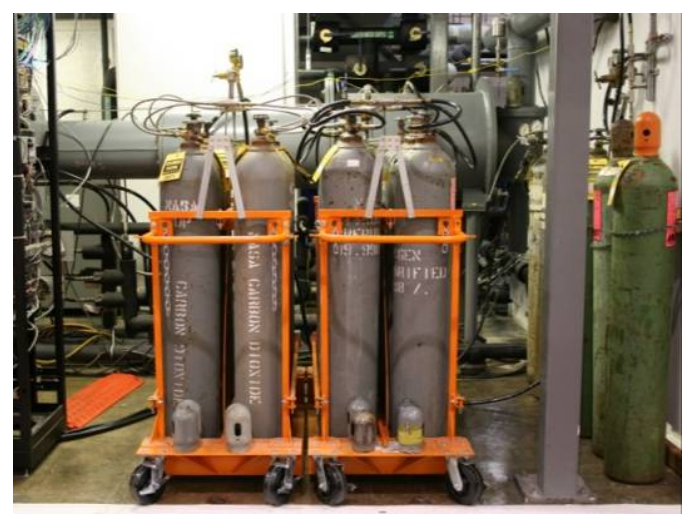

Figure 4. Test Gas Cylinders

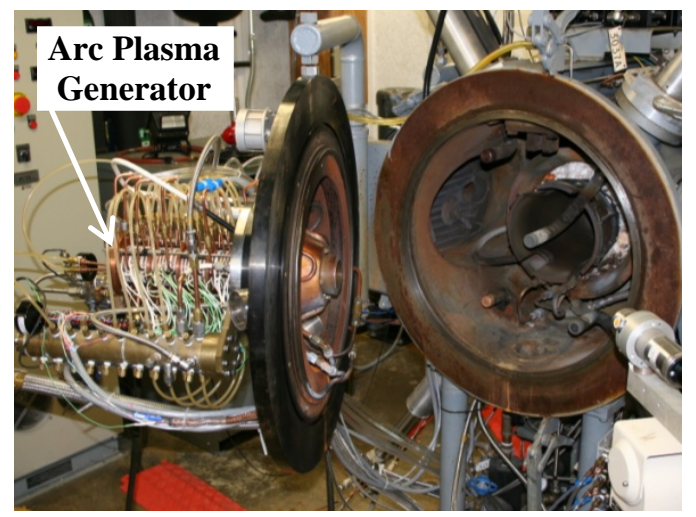

Figure 3. HYMETS Facility Test Setup

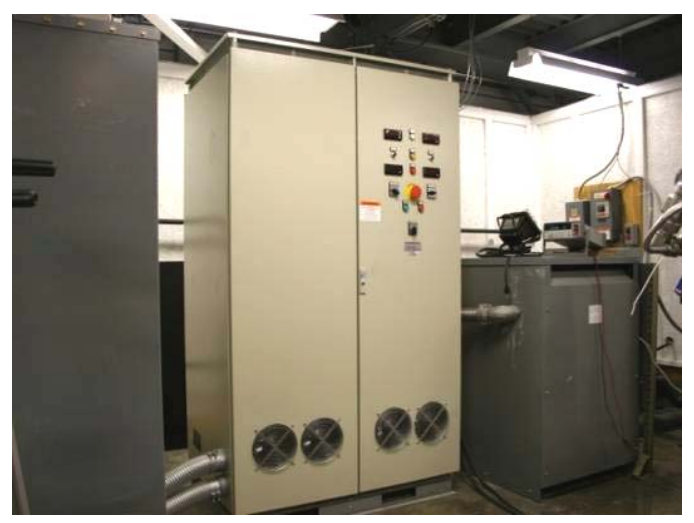

Figure 5. Power Supply and Induction Filter 


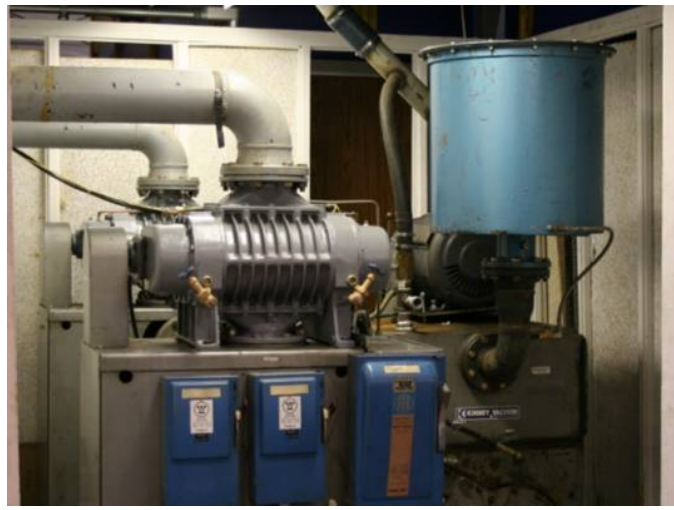

Figure 6. Mechanical Pumping System

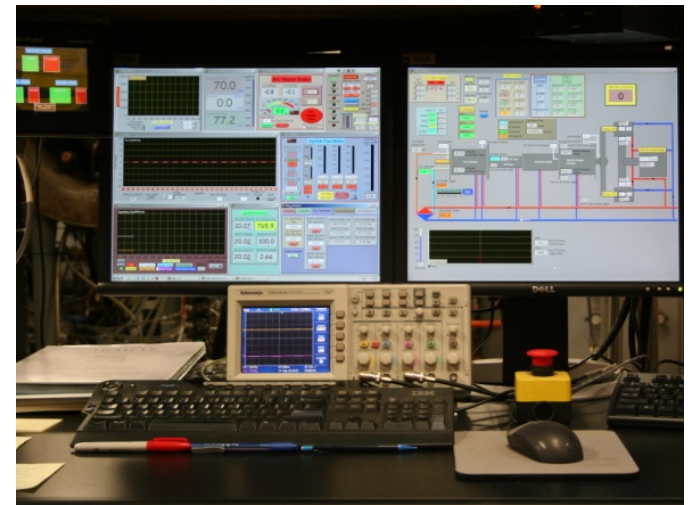

Figure 7. HYMETS Facility Control Software and Touch-Screen Module

\section{Facility Instrumentation}

A wide variety of instrumentation is used to determine the flow characteristics of the plasma in an arc-jet facility. ${ }^{19}$ Instrumentation used in the HYMETS facility consists of a Pitot tube which measures stagnation pressure, a $\mathrm{SiC}$ probe $^{20}$ which measures semi-catalytic hot-wall heat flux, a Gardon Gauge ${ }^{21}$ and a Copper Slug Calorimeter ${ }^{22,23}$ which measure fully-catalytic cold-wall heat flux, and a Teflon ${ }^{\circledR}$ Slug Calorimeter ${ }^{24,25}$ which measures non-catalytic cold-wall heat flux. The Gardon Gauge and the Pitot tube, shown in Figs. 8 and 9 respectively, are located on the two lower injection stings inside the test chamber. The Copper Slug Calorimeter, shown in Fig. 10, is located on one of two upper injection stings inside the test chamber. The Teflon ${ }^{\circledR}$ Slug Calorimeter, SiC probe, and a test specimen configuration are shown in Figs. 11, 12, and 13, respectively. Any one of these items can be located on the remaining upper injection sting. The standard geometry for HYMETS instrumentation consists of a 1.3-inch diameter flat-faced cylinder with a 0.125-inch edge radius. The test specimen configuration shown in Fig. 13 is of the same basic geometry, but includes a 0.9-inch-diameter 0.03-inch-deep recess on the flat-face of the cylinder due to the lip on the specimen holder. The bulk enthalpy of the plasma flow is determined by performing an energy balance on the arc plasma generator. ${ }^{26}$ A two-color (ratio) pyrometer and fullcolor digital video camera with variable exposure settings positioned outside the test chamber are remotely aimed at the specimen through a viewport on the test chamber door. The stagnation pressure, various heat fluxes, temperature, bulk enthalpy, and other facility parameters are recorded at $1000 \mathrm{~Hz}$. The test results in this paper focus on the bulk enthalpy calculation and the measurements made with the Pitot tube and the Copper and Teflon ${ }^{\circledR}$ Slug Calorimeters.

An energy balance is performed on the arc plasma generator in HYMETS to calculate the bulk enthalpy. The energy input to the arc plasma generator is determined by the product of voltage and current measurements. The energy removal from the arc plasma generator is determined by the product of the cooling water flow rate and the differential temperature measured across the inlet and outlet of the cooling water manifolds. Finally, the energy that remains in the arc plasma generator is divided by the total measured mass flow rate of the test gases. The bulk enthalpy is calculated using ${ }^{26}$

$$
H_{O}=\left(\frac{E I C_{1}-C_{2} C W C_{P} \rho \Delta T_{C W}}{M_{\text {Total }}}\right)
$$

where the constants $C_{1}$ and $C_{2}$ convert the energy input and output to the proper units respectively.

The Copper Slug Calorimeter used in HYMETS to determine fully-catalytic cold-wall heat flux consists of an un-cooled slug sensor element that is 0.5 -inches in diameter by 0.5 -inches-long with an un-cooled shroud that is 1.3 inches in diameter by 0.850 -inches-long and a flow-face edge radius of 0.125 -inches. The slug sensor element and shroud are fabricated out of oxygen-free high-conductivity (OFHC) copper. The slug sensor element has a 0.002inch-wide "insulating" air gap between it and the shroud, and is held in place using six cone-tipped set-screws. The slug sensor element also has a Type-K thermocouple mounted on its back surface to measure temperature rise. The length, diameter, and mass of the slug sensor element are measured prior to testing. The Copper Slug Calorimeter is inserted into a steady-state flow for 2-3 seconds so that it achieves a back-face temperature rise of several hundred 
degrees Fahrenheit, not to exceed a final temperature of $600^{\circ} \mathrm{F}$. The fully-catalytic cold-wall heat flux is calculated from the density of the OFHC copper slug sensor element, the temperature dependent specific heat capacity of the element, the length of the element, and the slope of the temperature rise from the linear portion of the temperature response curve for the Type-K thermocouple using ${ }^{22}$

$$
\dot{q}_{F C C W}=\rho C_{P}(T) l\left(\frac{\Delta T_{F C C W}}{\Delta t}\right)
$$

The uncertainty of the resulting method given by Eq. (2) is assumed to be $+/-10 \%{ }^{23}$

The Teflon ${ }^{\circledR}$ Slug Calorimeter used in HYMETS to determine non-catalytic cold-wall heat flux consists of a slug sensor element with a shroud made from virgin Teflon ${ }^{\circledR}$ PTFE (poly-tetra-fluoro-ethylene). Teflon ${ }^{\circledR}$ PTFE is a non-catalytic, low-temperature, subliming ablator. The design of the slug sensor element and shroud are similar to the design for the Copper Slug Calorimeter without positioning set-screws and the Type-K thermocouple. The slug sensor element has an interference fit with the shroud so that it is easily assembled and disassembled. The length, diameter, and mass of the slug sensor element are measured before and after testing. The Teflon ${ }^{\circledR}$ Slug Calorimeter is inserted into a steady-state flow for 30 seconds according to Refs. 24 and 25. The non-catalytic cold-wall heat flux is calculated from the change in mass of the slug sensor element, the amount of time it was exposed to the flow, the effective hemispherical radius of the slug sensor element, the flat-face radius of the element, and the stagnation pressure at the steady-state flow condition using ${ }^{25}$

$$
\dot{q}_{N C C W}=\left[\frac{\dot{m}_{T} R_{\text {eff }}^{0.21}}{0.0046 P_{\text {stag }}^{0.24}}\right]^{\left(\frac{1}{0.55}\right)}
$$

where

$$
R_{\text {eff }}=3.3 R_{\text {FlatFace }}
$$

Equation (3) has an assumed uncertainty of $+/-10 \%$, and is based on the correlation of an extensive collection of arcjet data on Teflon ${ }^{\circledR}$ PTFE for a variety of geometries and flow conditions. ${ }^{24,25}$

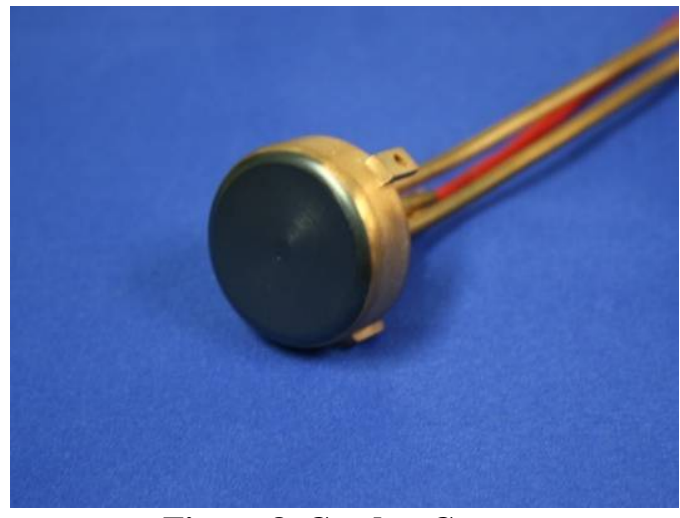

Figure 8. Gardon Gauge

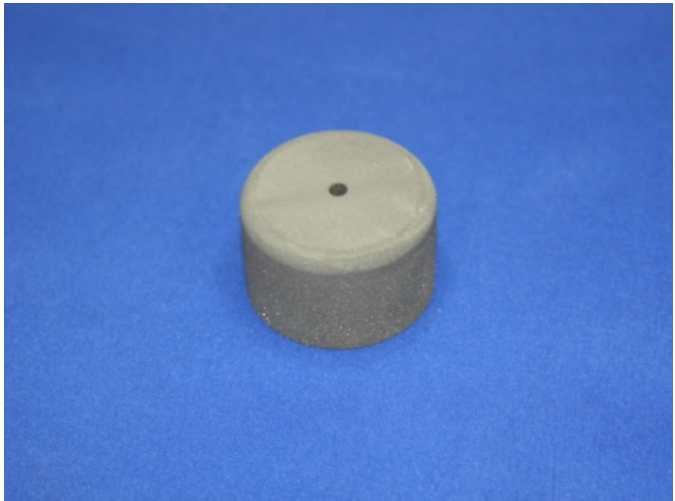

Figure 9. Pitot Tube 


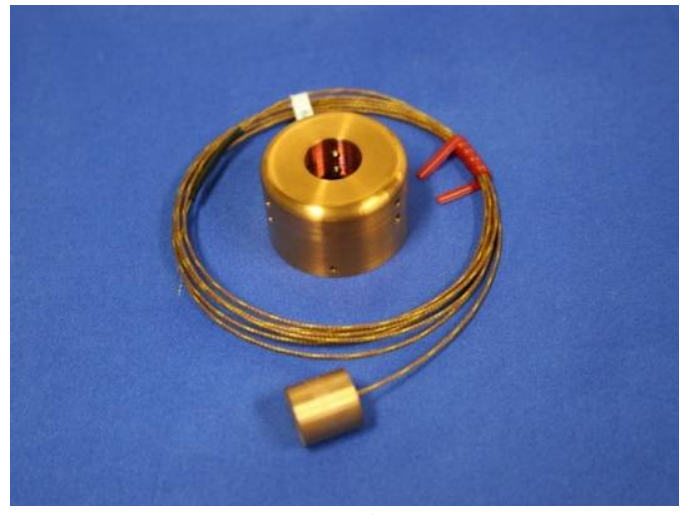

Figure 10. Copper Slug Calorimeter

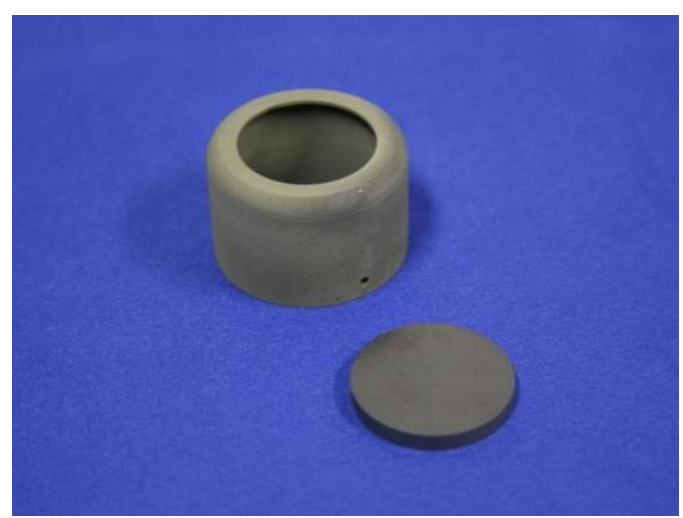

Figure 12. SiC Probe

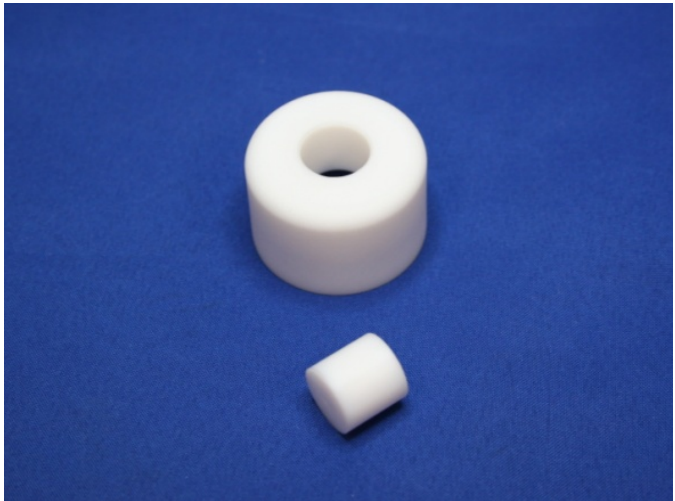

Figure 11. Teflon ${ }^{\circledR}$ Slug Calorimeter

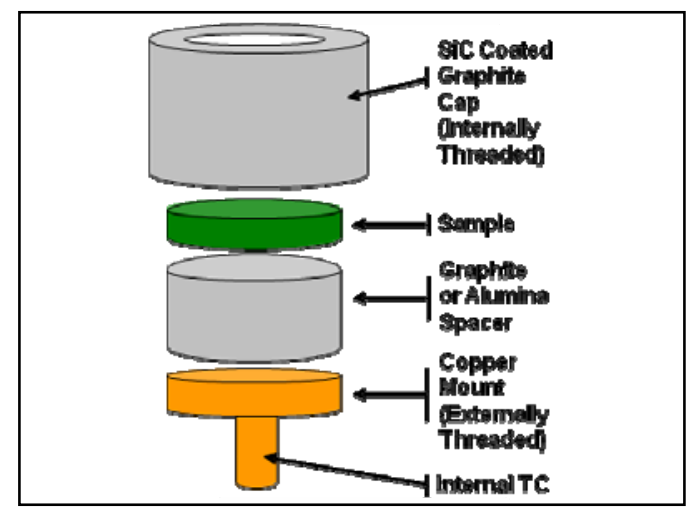

Figure 13. Specimen Holder Configuration

\section{Facility $\mathrm{CO}_{2}$ Modification and Operation}

The implementation of $\mathrm{CO}_{2}$ as a test gas in the HYMETS facility was performed incrementally. The first step was to add a small percentage of $\mathrm{CO}_{2}$ gas into the arc plasma generator to the $\mathrm{N}_{2}, \mathrm{O}_{2}$, and Ar gasses already present. The percentage of $\mathrm{CO}_{2}$ gas was then increased, simultaneously decreasing the percentages of $\mathrm{N}_{2}$ and $\mathrm{O}_{2}$, while maintaining electric arc stability and arc plasma generator integrity. The current operational $\mathrm{CO}_{2}$ gas ratio for HYMETS is $24 \% \mathrm{~N}_{2}, 71 \% \mathrm{CO}_{2}$, and $5 \%$ Ar by volume. This provides a $25 \%$ to $75 \%$ ratio by volume of $\mathrm{N}_{2}$ to $\mathrm{CO}_{2}$ when $\mathrm{Ar}$ is excluded from the mix. This current ratio is closer to achieving the actual gas ratio for the Martian atmosphere of $3 \% \mathrm{~N}_{2}$ to $97 \% \mathrm{CO}_{2}$ than historical attempts. For reference, the operational air ratio for HYMETS is $75 \% \mathrm{~N}_{2}, 20 \% \mathrm{O}_{2}$, and $5 \% \mathrm{Ar}$ by volume. This provides a $79 \%$ to $21 \%$ ratio by volume of $\mathrm{N}_{2}$ to $\mathrm{O}_{2}$ when $\mathrm{Ar}$ is excluded from the mix, which is the actual gas ratio for the Earth atmosphere. The arc plasma generator gas injection locations for both air and $\mathrm{CO}_{2}$ operation are shown in Fig. 14. A fixed amount of $\mathrm{N}_{2}$ was retained near the cathode in the arc plasma generator to prevent oxidation. $\mathrm{CO}_{2}$ was supplied from a compressed gas cylinder, which contained both gaseous and liquid $\mathrm{CO}_{2}$ at room temperature. It was noted that during sustained operation of the facility with $\mathrm{CO}_{2}$, liquid $\mathrm{CO}_{2}$ boiled off in the cylinder to satisfy the gaseous $\mathrm{CO}_{2}$ demand. The heat removed from the cylinder to boil off the liquid created a temperature drop in the gas. When the low temperature $\mathrm{CO}_{2}$ gas expanded through the pressure regulator for the $\mathrm{CO}_{2}$ cylinder, dry-ice formed in the regulator blocking the flow of gas through the distribution lines. A tube and shell heat exchanger for the distribution lines with three pressureregulated stages was created to prevent this formation of dry-ice. Even with the heated distribution lines and regulators, it was still possible for dry-ice to form inside the cylinder if a sufficient volume of gas was removed over a short time. To avoid removing an excessive volume of gas, $\mathrm{CO}_{2}$ was supplied from eight cylinders simultaneously. It was also noted that sustained operation of the facility with $\mathrm{CO}_{2}$ introduced a "soot-like" deposit onto the components of the arc plasma generator. The build-up of the "soot-like" deposits decreased the stability of the electric arc and increased the risk of its attachment to a segment resulting in damage to the arc plasma generator. The "soot-like" deposits require regular cleaning of the arc segments with a wire brush. 
The second step in implementing $\mathrm{CO}_{2}$ was to assess the industrial and environmental safety implications associated with mixing $\mathrm{CO}_{2}$ and $\mathrm{N}_{2}$ because of the potential to produce harmful molecules like Carbon Monoxide (CO), Cyanide (CN), and Nitric Oxide (NO). The production of $\mathrm{CO}$ and $\mathrm{O}_{2}$ creates a possible explosion hazard within the heat exchanger and mechanical pumping system, as $\mathrm{CO}$ is a fuel. The upper explosive limit and lower explosive limit as provided by the Material Safety Data Sheet (MSDS) for CO in air is $74 \%$ and $12.5 \%$ respectively. A residual gas analysis (RGA) of exhaust gasses in the section between the heat exchanger and mechanical pumping system performed by Sandia National Laboratories revealed that half of the $\mathrm{CO}_{2}$ injected into the arc plasma generator was disassociated into its constituents. ${ }^{27}$ If these constituents were assumed to be entirely composed of $\mathrm{CO}$ and $\mathrm{O}_{2}$, then $\mathrm{CO}$ would make up $35.6 \%$ of the heat exchanger and mechanical pumping system gasses, which is within the explosive limit. However, $\mathrm{CO}$ and $\mathrm{O}_{2}$ mixtures are not combustible below about 25 torr $^{28}$, and the maximum pressure in the heat exchanger and mechanical pumping system is 25.4 torr. To further mitigate the explosive mix of $\mathrm{CO}$ and $\mathrm{O}_{2}$ in the heat exchanger and mechanical pumping system, the facility is purged during start-up and shutdown using only the inert gasses $\mathrm{N}_{2}$ and $\mathrm{Ar}$ when operating with $\mathrm{CO}_{2} \cdot{ }^{29}$

The production of $\mathrm{CN}$ during facility operation with $\mathrm{CO}_{2}$ and $\mathrm{N}_{2}$ would create a hazardous and undesirable work environment as $\mathrm{CN}$ is a poison. Fortunately RGA measurements indicated no detectable levels of particulate $\mathrm{CN}$ or Hydrogen Cyanide (HCN) in the facility's exhaust. ${ }^{27}$ Additional surface swabs and air samples taken inside the test chamber before and after facility operation also indicated no detectable levels of particulate $\mathrm{CN}$ or $\mathrm{HCN}^{30}$ Particulate CN was found in the pump oil for the mechanical pumping system. ${ }^{31}$ The lack of particulate CN or HCN in the test chamber samples and RGA measurements upstream from the mechanical pumps indicates a different method of particulate $\mathrm{CN}$ creation than from the arc plasma generator. The particulate $\mathrm{CN}$ in the mechanical pumps could have formed through a reaction between the hydrocarbon pump oil and the hot $\left(200^{\circ} \mathrm{F}\right)$, partially disassociated nitrogen in the exhaust gasses moving through it. Industrial safety personnel noted that because the particulate CN is entrapped in pump oil, which itself is considered a hazardous material, the standard method for handling and disposal was sufficient.

Finally, the production of NO during facility operation with $\mathrm{CO}_{2}$ and $\mathrm{N}_{2}$ means that HYMETS would have to be considered a pollution source. Nitric Oxide production was confirmed by RGA measurements ${ }^{27}$ and NO Planar Laser Induced Fluorescence (PLIF) measurements. ${ }^{32}$ Emission of NO from the HYMETS facility is currently regulated as part of the NASA Langley air permit for operation with $\mathrm{N}_{2}$ and $\mathrm{O}_{2}{ }^{33}$ There is sufficient margin in the HYMETS portion of the Langley air permit to absorb the additional $\mathrm{NO}$ that is produced by operation with $\mathrm{CO}_{2}$ and $\mathrm{N}_{2}$. No further restrictions were required for operation with $\mathrm{CO}_{2}$ and $\mathrm{N}_{2}$ since the emission of $\mathrm{CO}_{2}, \mathrm{~N}_{2}$, and their constituents (i.e. CO, CN, C, N, $\mathrm{O}_{2}$, and O) are not regulated in the Commonwealth of Virginia.

The remaining step is to better simulate the Martian atmosphere by increasing the operational gas ratio of $\mathrm{CO}_{2}$ to $97 \% \mathrm{CO}_{2}$ to $3 \% \mathrm{~N}_{2}$ by volume. Higher ratios of $\mathrm{CO}_{2}$ to $\mathrm{N}_{2}$ than the current ratio, $75 \% \mathrm{CO}_{2}$ to $25 \% \mathrm{~N}_{2}$ by volume, result in unacceptable oxidation of the cathode. A possible method of achieving higher ratios is to introduce CO near the cathode to reduce the amount of $\mathrm{N}_{2}$ needed to shield the cathode. The tungsten button in the cathode is not easily oxidized by $\mathrm{CO}^{34}$ The $\mathrm{CO}$ would then be balanced by introducing a chemically equivalent amount of $\mathrm{O}_{2}$ closer to the anode. In addition to bringing the test gas ratio closer to that of the actual Martian atmosphere, the facility would be able to take advantage of the heat of formation of $\mathrm{CO}$ and $\mathrm{O}_{2}$ in the production of $\mathrm{CO}_{2}$ to increase the bulk enthalpy and heat flux of the test conditions. An analysis determined this would be the best way to achieve MSL-like entry conditions without significant modifications to the facility. ${ }^{35}$ Since CO is both a fuel and a poison, an industrial safety study determined that the $\mathrm{CO}$ would have to be located in an open atmosphere outside of the facility's building and piped in for testing. The time and cost associated with building a cylinder storage area and gas distribution system for CO prevented its use in this study.

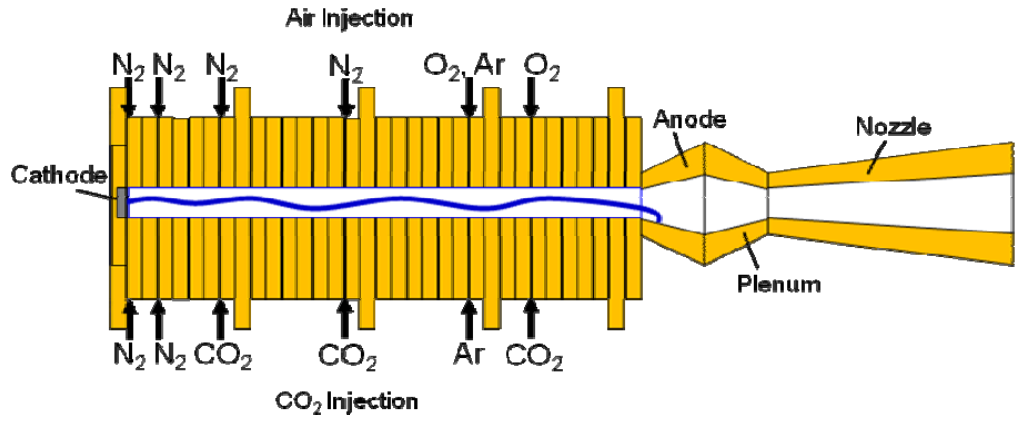

Figure 14. HYMETS Arc Plasma Generator Test Gas Injection Schematic 


\section{Test Approach}

\section{A. Test Conditions}

A range of test conditions, or envelope map, for the HYMETS facility was performed with a standard and oxygen-rich Earth atmosphere and a simulated Martian atmosphere as defined by the test gas constituents listed in Table 3. The parameters that can be controlled when operating the facility are the arc current and the test gas mass flow rate. A particular combination of these parameters, a so-called facility setpoint, yields a test environment with a certain bulk enthalpy, heat flux, and stagnation pressure, which are the desired parameters for materials testing. An envelope map consists of running the facility at a number of setpoints to determine the range of achievable parameters. A complete matrix of the HYMETS facility setpoints is listed in Table 4. The current and mass flow rate setpoints higher than 300 Amps in Table 4 were unavailable at the time of this testing because of an instability within the power supply which limited its maximum current output. The power supply instability has since been fixed, and these setpoints are now available for future testing. The number of setpoints at which tests could be conducted was further reduced by limited availability of Teflon ${ }^{\circledR}$ Slug Calorimeters. The tests in this paper were conducted at the gray highlighted setpoints listed in Table 4. Facility operating conditions including bulk enthalpy, heat flux, stagnation pressure, mass flow rate, arc current, and arc voltage were recorded at all times during facility operation. Results from these tests were used to develop comparisons between enthalpies, heating rates, and stagnation pressures for the three different test atmospheres. Of particular interest is a comparison of results between the oxygen-rich Earth atmosphere and the simulated Martian atmosphere to assess the adequacy of testing in an oxygen-rich Earth atmosphere as a replacement for testing with $\mathrm{CO}_{2}$. The oxygen-rich Earth atmosphere in Table 3 contains $27.6 \% \mathrm{O}_{2}$ by weight, which is equivalent to the simulated Martian atmosphere which can generate $27.3 \% \mathrm{O}_{2}$ by weight from the disassociation of $\mathrm{CO}_{2}{ }^{4}$

Table 3. HYMETS Test Atmospheres

\begin{tabular}{|l|c|c|c|c|c|}
\hline \multirow{2}{*}{\multicolumn{1}{|c|}{ Test Atmosphere }} & \multicolumn{4}{|c|}{ Test Gases } & \multirow{2}{*}{ Measurement Basis } \\
\cline { 2 - 5 } & $\mathbf{N}_{2}$ & $\mathbf{O}_{2}$ & $\mathbf{C O}_{2}$ & $\mathbf{A r}$ & \\
\hline Standard Earth Atmosphere & $75 \%$ & $20 \%$ & --- & $5 \%$ & By Volume (or Mole) \\
\hline Oxygen-Rich Earth Atmosphere & $71 \%$ & $24 \%$ & --- & $5 \%$ & By Volume (or Mole) \\
\hline Simulated Martian Atmosphere & $24 \%$ & --- & $71 \%$ & $5 \%$ & By Volume (or Mole) \\
\hline
\end{tabular}

Table 4. HYMETS Facility Setpoint Matrix for Test Atmospheres

\begin{tabular}{|c|l|l|l|l|l|l|l|l|l|l|l|}
\hline $\begin{array}{c}\text { Current } \\
\text { (Amps) }\end{array}$ & \multicolumn{10}{|c|}{$\begin{array}{c}\text { Mass Flow Rate } \\
\left(\mathbf{l} \mathbf{b}_{\mathbf{m}} / \mathbf{s} \text { ) }\right.\end{array}$} \\
\hline 100 & 0.0048 & 0.0072 & 0.0096 & 0.0120 & 0.0145 & 0.0169 & 0.0193 & 0.0217 & 0.0241 & & \\
\hline 150 & 0.0048 & 0.0072 & 0.0096 & 0.0120 & 0.0145 & 0.0169 & 0.0193 & 0.0217 & 0.0241 & & \\
\hline 200 & 0.0048 & 0.0072 & 0.0096 & 0.0120 & 0.0145 & 0.0169 & 0.0193 & 0.0217 & 0.0241 & & \\
\hline 250 & & 0.0072 & 0.0096 & 0.0120 & 0.0145 & 0.0169 & 0.0193 & 0.0217 & 0.0241 & 0.0265 & \\
\hline 300 & & 0.0072 & 0.0096 & 0.0120 & 0.0145 & 0.0169 & 0.0193 & 0.0217 & 0.0241 & 0.0265 & \\
\hline 350 & & & 0.0096 & 0.0120 & 0.0145 & 0.0169 & 0.0193 & 0.0217 & 0.0241 & 0.0265 & 0.0289 \\
\hline 400 & & & 0.0096 & 0.0120 & 0.0145 & 0.0169 & 0.0193 & 0.0217 & 0.0241 & 0.0265 & 0.0289 \\
\hline
\end{tabular}

\section{B. Test Data}

An effort was made to reduce the precision and bias uncertainties in the test results to a $95 \%$ confidence interval. The precision uncertainty was reduced by using a median filter processing technique to remove spurious noise from the recorded parameters. The median filter ${ }^{18}$ consists of a data point bounding interval which is set by the left and right rank, or measurement points. The values within the interval bounded by the rank are arranged in ascending numerical order and the median value is found. The filtered curve is the median value (middle-most point) for the corresponding interval. Given the noise characteristics of the HYMETS parameters, a left and right rank of 2 measurement points was selected. The bias uncertainty for the filtered parameters was determined by the accuracy of the transducer. These values are typically reported as a percentage of the instrument's full scale range or as a percentage of the reading with a 95\% confidence level. The precision and bias uncertainties were then combined to determine the total uncertainty for each parameter. 


\section{European Test Conditions}

Additional tests were performed in HYMETS with test conditions replicating those from an experimental study of several European plasma facilities presented in Refs. 36 and 37. The sensors used in the European study consisted of SiC probes, Gardon Gauges, Copper Calorimeter Probes, and Heat Flux Micro-sensors. The study utilized three standard model geometries. The third geometry in the study, a 1.97-inch flat-faced cylinder with 0.45inch-edge-radius, was the most similar to HYMETS. The European plasma facilities that tested with this geometry included the segmented-arc-heated L3K facility at the German Aerospace Center (DLR) ${ }^{8}$, the thermal or magnetoplasma-dynamic Plasma Wind Tunnels (PWK) 1 and 2 at the Institute of Space Systems at the University of Stuttgart (IRS) ${ }^{9}$, the Huels arc-heated SIMOUN and inductively-heated COMETE facilities at the European Aeronautic Defense and Space Company (EADS $)^{10}$, and the inductively-heated PLASMATRON facility at the von Karman Institute $(\mathrm{VKI})^{11}$. The representative and comparable standard Earth atmosphere flow test conditions are listed in Table 5. The stagnation pressure, bulk enthalpy, and heat flux measurements made in the HYMETS facility at these flow test conditions were compared to those made in the European facilities.

Table 5. HYMETS Flow Test Conditions for Comparison with European

\begin{tabular}{|l|l|c|}
\hline \multicolumn{1}{|c|}{ Test Conditions } & Stagnation Pressure & Bulk Enthalpy \\
\hline Flow Test Condition I (FTC-I) & $0.0345 \mathrm{~atm}(35 \mathrm{hPa})$ & $3870 \mathrm{Btu} / \mathrm{lb}_{\mathrm{m}}(9 \mathrm{MJ} / \mathrm{kg})$ \\
\hline Flow Test Condition II (FTC-II) & $0.0345 \mathrm{~atm}(35 \mathrm{hPa})$ & $5589 \mathrm{Btu} / \mathrm{lb}_{\mathrm{m}}(13 \mathrm{MJ} / \mathrm{kg})$ \\
\hline
\end{tabular}

\section{Test Results}

The effect of the test atmosphere on facility performance is assessed by comparing the bulk enthalpy, various measured heat flux, and stagnation pressure at the same facility setpoint for the three simulated entry environments. All parameters are displayed with respect to the mass flow rate to provide a clear relationship between the facility setpoints and facility performance. A comparison of test results for a standard Earth atmosphere and simulated Martian atmosphere is presented. A comparison of test results for an oxygen-rich Earth atmosphere and the simulated Martian atmosphere is also presented. These comparisons are made to assess the adequacy of testing in a standard or an oxygen-rich Earth atmosphere as a replacement for testing with $\mathrm{CO}_{2}$. In addition to the comparisons, the results presented in the following subsections establish the current range of test conditions for the HYMETS facility.

\section{A. Comparison of Simulated Martian and Standard Earth Atmosphere}

A representative image of the plasma flow for the standard Earth atmosphere is shown in Fig. 15 where the plasma exhibits a pinkish-orange glow. A representative image of the plasma flow for the simulated Martian atmosphere is shown in Fig. 16 where the plasma exhibits a whitish-blue glow. The constituents in the plasma determine its color. Research to determine the constituents of the plasma in HYMETS will be described in a later paper.

Bulk enthalpy is a parameter used to characterize the flow environment when comparing performance of different materials and for extrapolating test results to flight. The comparison of the bulk enthalpy for the standard Earth and simulated Martian atmospheres in Fig. 17 shows that the simulated Martian bulk enthalpy values are higher than the standard Earth values for each of the facility setpoints. Examining the variables that go into Eq. (1) for the calculation of the bulk enthalpy, the current and mass flow rates for each atmosphere are identical per the test conditions. The arc plasma generator voltage is $4.4 \%$ more for the simulated Martian atmosphere than it is for the standard Earth atmosphere based on the root-mean-square (RMS) of the percent differences between the two. The RMS value was determined by first taking the percent difference of a Martian value from an Earth value at each of the facility setpoints for a given parameter. These individual setpoint percent differences were then combined into one value for that parameter using the RMS method, in an effort to provide a single measure of the overall difference between the two atmospheres. The energy removed by the cooling water from the arc plasma generator is 21.7\% less for the simulated Martian atmosphere than it is for the standard Earth atmosphere based on the RMS of the percent differences between the two. The contributions from these two variables create the offset in the bulk enthalpies between the simulated Martian and standard Earth atmospheres. The difference in voltage can be attributed to the differences in the ionization and disassociation energies for each of the test gasses that make up the 
two atmospheres. The reason for the greater energy loss to the cooling water for the standard Earth atmosphere over the simulated Martian atmosphere is unknown at this time. The RMS percent difference with the maximum and minimum of the individual setpoint percent differences between the two atmospheres for the bulk enthalpy are presented in Table 6. The RMS percent total uncertainty with the maximum and minimum of the individual setpoint percent total uncertainties in the bulk enthalpy measurement are also presented in Table 6 for each atmosphere. The total uncertainties for the standard Earth and simulated Martian atmospheres are similar because the measurements for the two atmospheres were made using the same instruments and data acquisition system.

Heat flux is a parameter chosen to establish the environment in which a material must perform. Two types of cold-wall heat flux measurements were made. The fully-catalytic cold-wall heat flux is measured by the Copper Slug Calorimeter. The non-catalytic cold-wall heat flux is measured by the Teflon ${ }^{\circledR}$ Slug Calorimeter. The catalytic energy, or fully-catalytic heat flux minus the non-catalytic heat flux, is the energy contributed by the recombination of the disassociated gas constituents when they come in contact with a catalytic surface. The non-catalytic heat flux provides a measure of the heat energy in the plasma. The fully-catalytic heat flux provides a measure of the total energy in the plasma, that is the heat energy plus the catalytic energy. Comparisons of the fully-catalytic and noncatalytic heat flux measurements for the two atmospheres are provided in Figs. 18 and 19, respectively. The heat flux measurements for the simulated Martian atmosphere at the 100 Amp current setpoint are lower than the standard Earth atmosphere for each of the mass flow rates. At the $200 \mathrm{Amp}$ current setpoint, the heat flux measurements for the simulated Martian atmosphere are higher than the standard Earth atmosphere for the lower mass flow rates, but then become lower than the standard Earth atmosphere as the mass flow rates increase. Finally, the heat flux measurements for the simulated Martian atmosphere at the $300 \mathrm{Amp}$ current setpoint are higher than the standard Earth atmosphere for each of the mass flow rates. The RMS percent difference with the maximum and minimum of the individual setpoint percent differences between the two atmospheres for the fully-catalytic and noncatalytic heat flux measurements are presented in Table 6. The RMS percent total uncertainty with the maximum and minimum of the individual setpoint percent total uncertainties in these measurements for each atmosphere are also presented in Table 6. A comparison of the percentages of the catalytic energy in the plasma for the two atmospheres is provided in Fig. 20. The standard Earth atmosphere appears to have more catalytic energy for each of the facility setpoints than the simulated Martian atmosphere. The reason for this is unknown. However, the trends exhibited by the catalytic energy in Fig. 20 are expected. At low mass flow rates, and therefore low partial gas pressures, the plasma for the two atmospheres is highly disassociated contributing a higher amount of catalytic energy. As the mass flow rates increase, the partial pressure of each test gas increases reducing the amount of disassociation and decreasing the amount of catalytic energy.

Finally, the stagnation pressure is also a parameter chosen to establish the environment in which a material must perform. Achieving a stagnation pressure test condition is usually secondary to achieving a bulk enthalpy or heat flux test condition. The stagnation pressure is therefore optimized to be close to the desired test condition. A comparison of the stagnation pressures for the two atmospheres is provided in Fig. 21. The stagnation pressures vary almost linearly with mass flow rate for the two atmospheres. A similar trend to that found in the heat flux measurement comparisons is present in the stagnation pressures for the standard Earth and simulated Martian atmospheres at each of the current setpoints. The RMS percent difference with the maximum and minimum of the individual setpoint percent differences between the two atmospheres for the stagnation pressure are presented in Table 6. The RMS percent total uncertainty with the maximum and minimum of the individual setpoint percent total uncertainties in the stagnation pressure measurement are also presented in Table 6 for each atmosphere. The total uncertainties for the standard Earth and simulated Martian atmospheres are again similar because the measurements were made using the same instruments and data acquisition system. The low total uncertainties for the stagnation pressures and the scale of the y-axis make the error bars appear absent from Fig. 21.

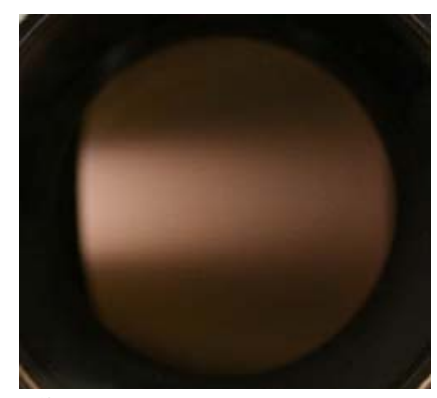

Figure 15. Standard Earth Atmosphere Plasma

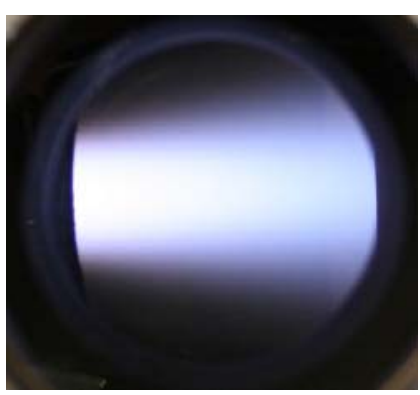

Figure 16. Simulated Martian Atmosphere Plasma 


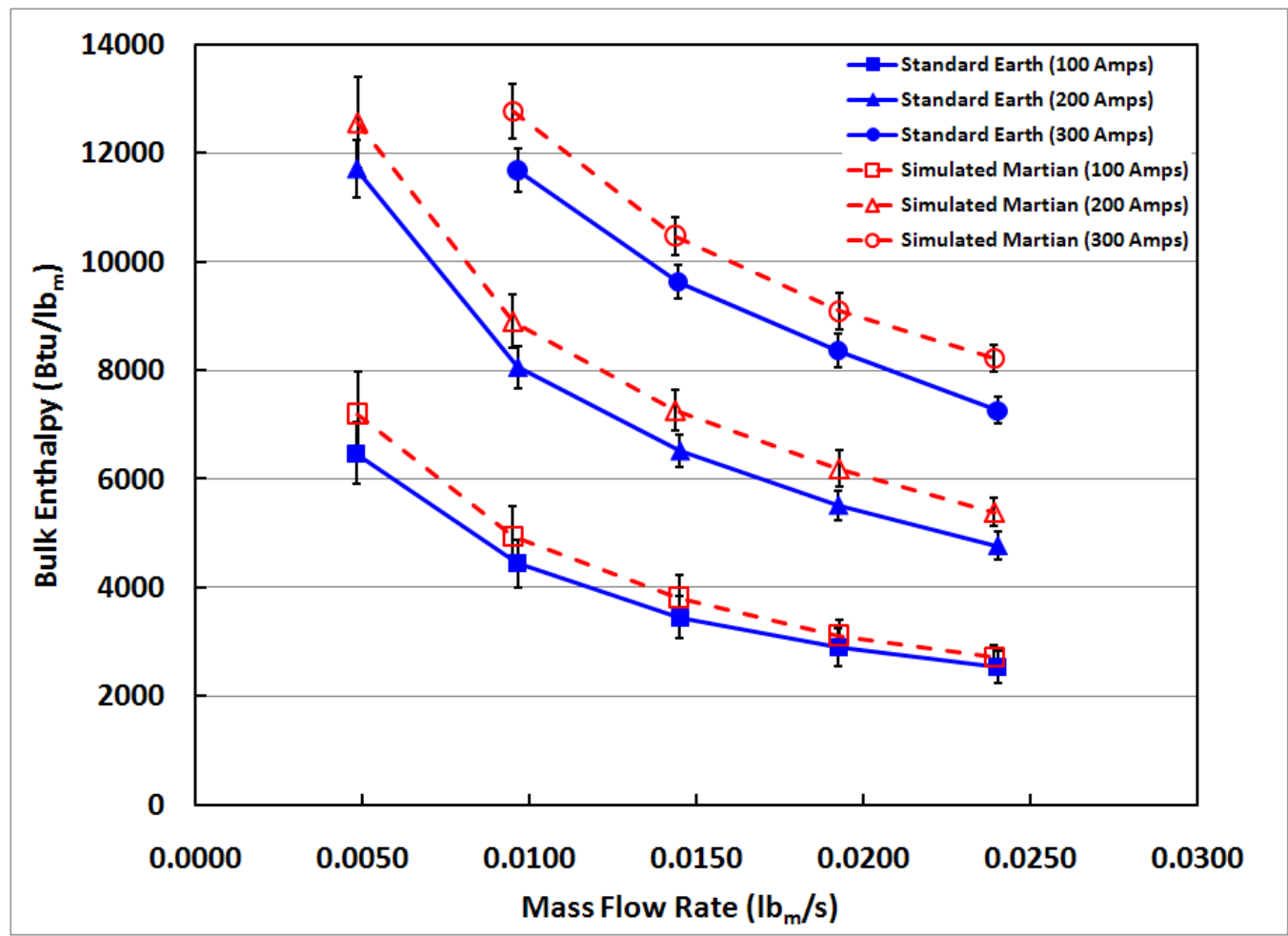

Figure 17. Bulk Enthalpy Comparison

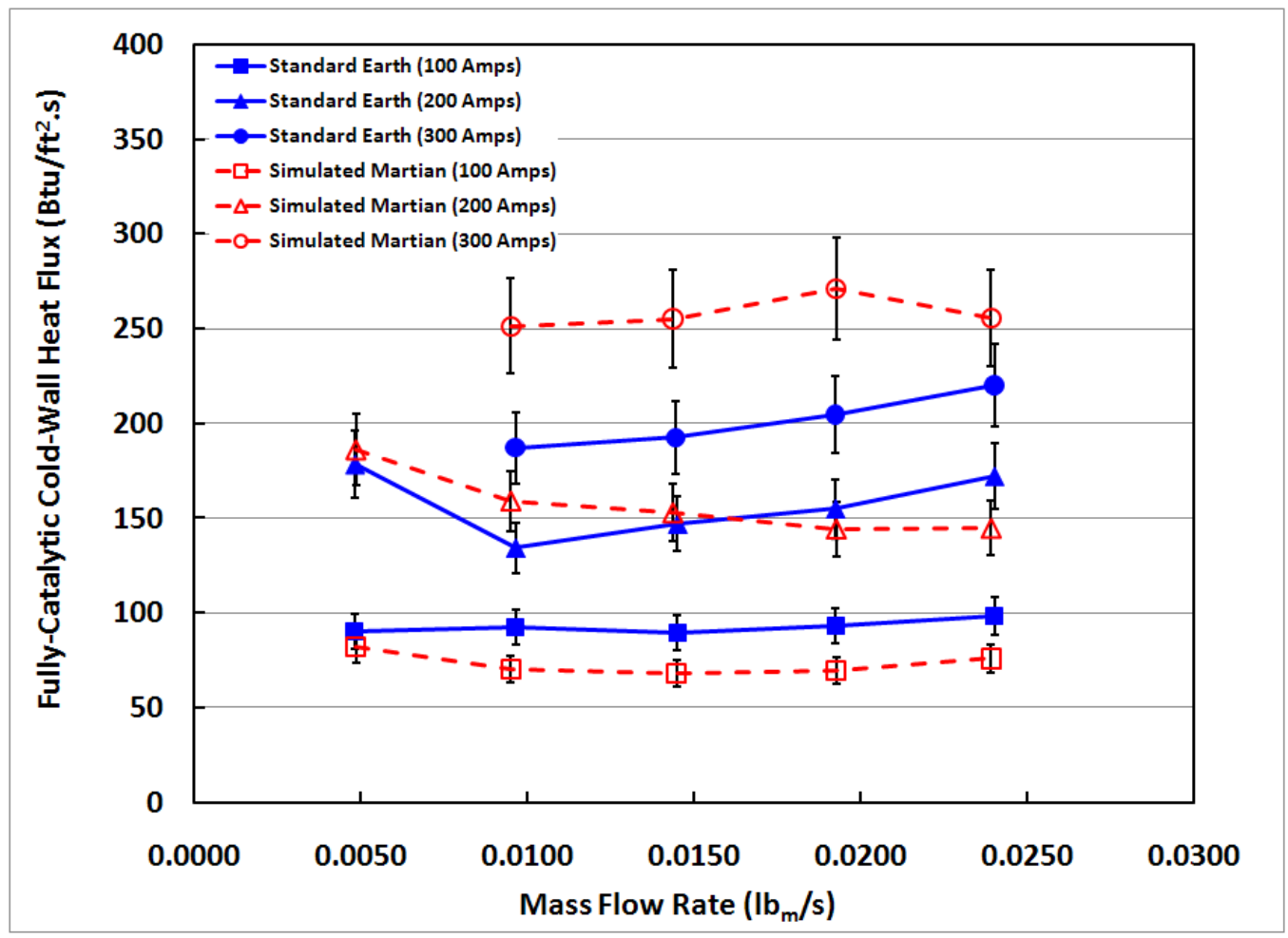

Figure 18. Copper Slug Calorimeter Cold-Wall Heat Flux Comparison 


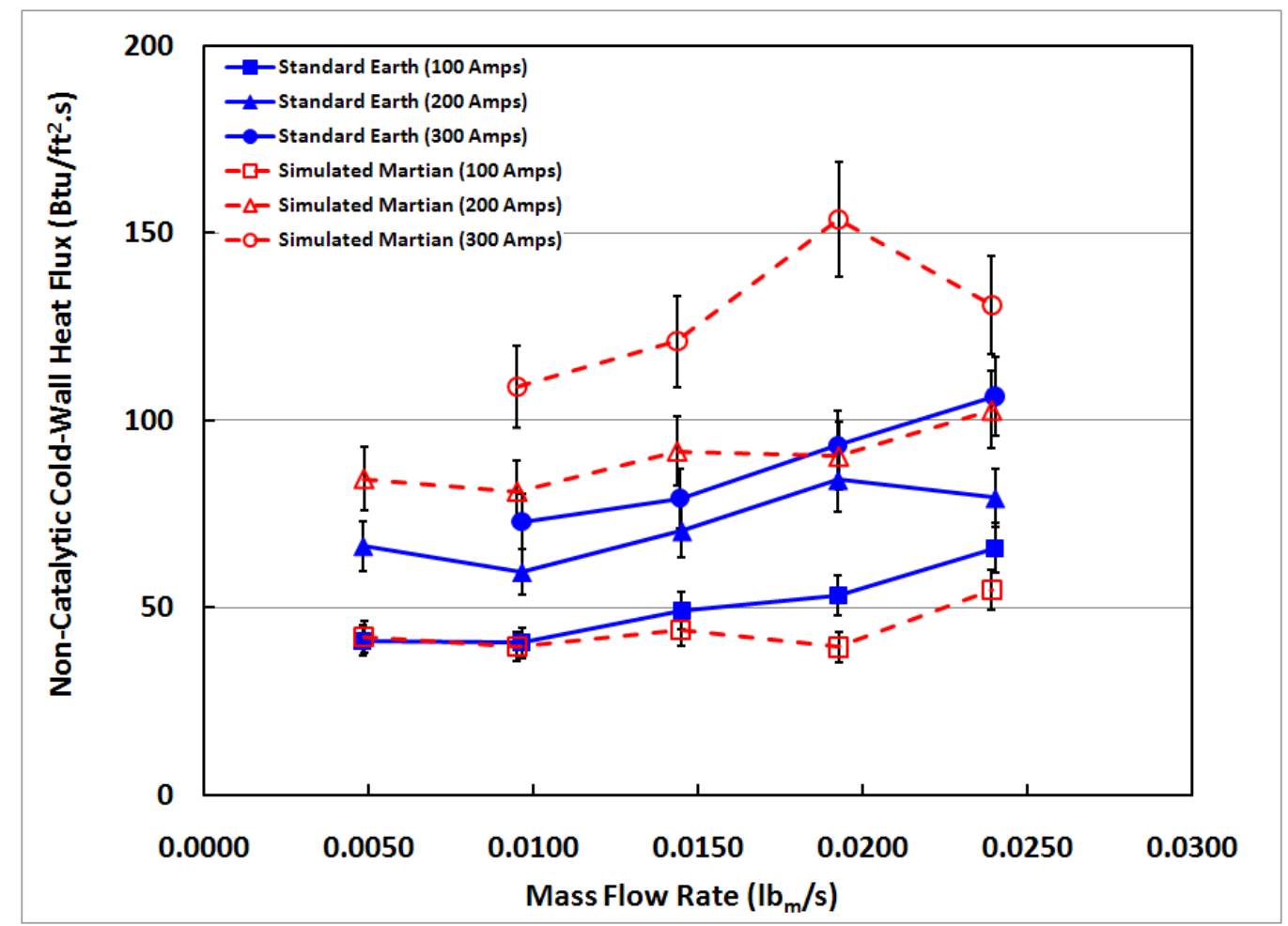

Figure 19. Teflon ${ }^{\circledR}$ Slug Calorimeter Cold Wall Heat Flux Comparison

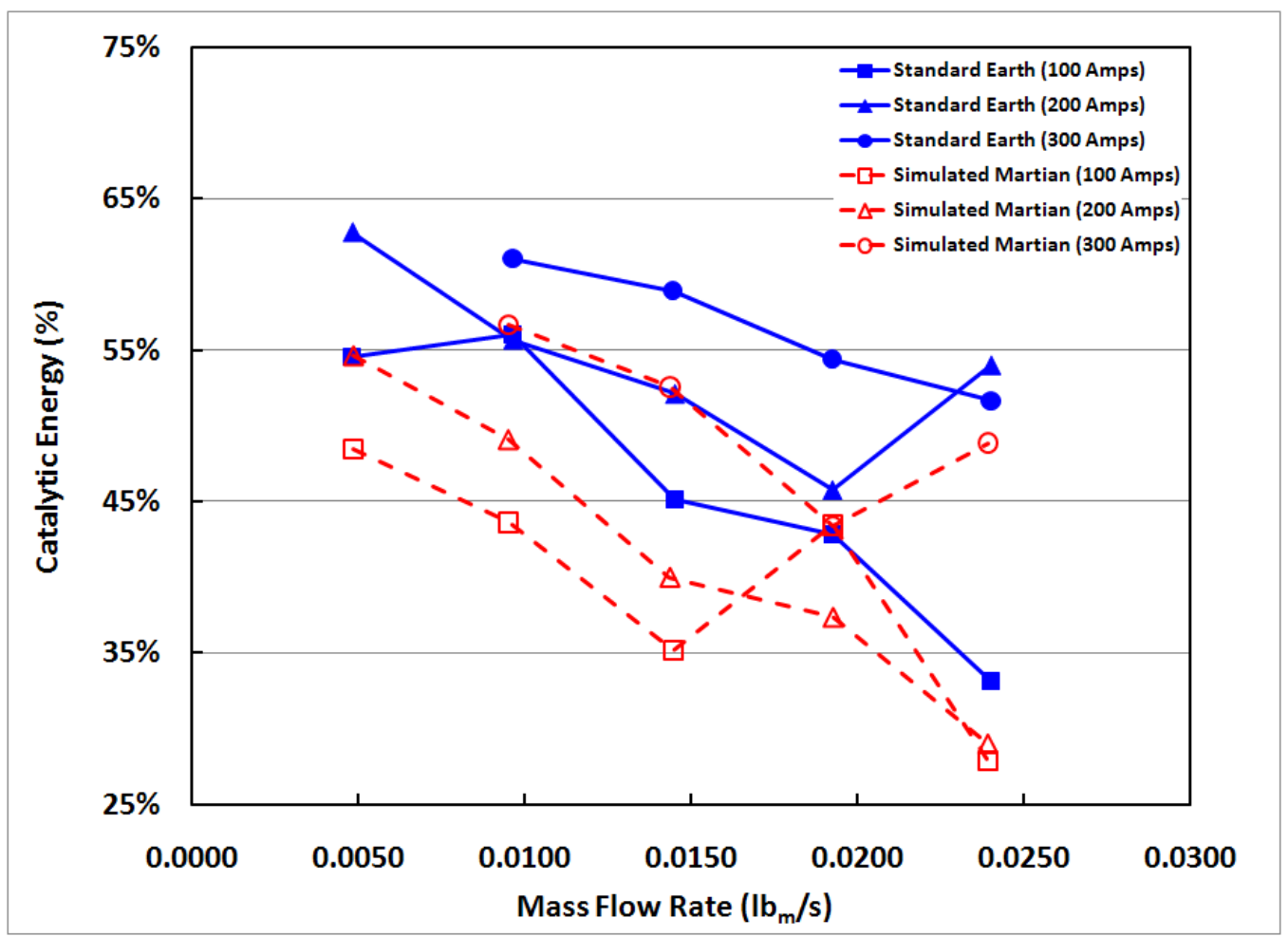

Figure 20. Catalytic Energy in the Plasma Comparison 


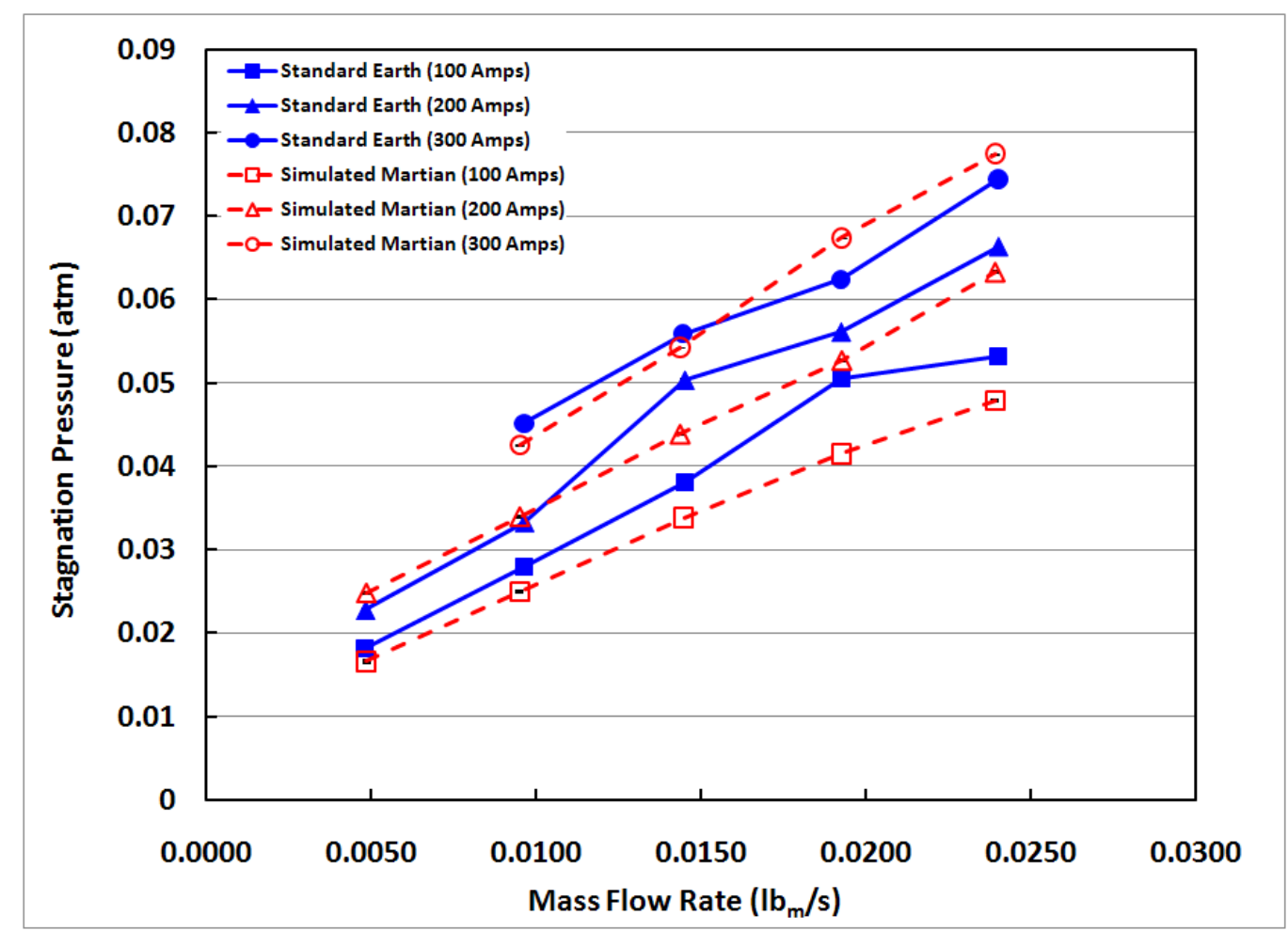

Figure 21. Stagnation Pressure Comparison

Table 6. Standard Earth and Simulated Martian Measurement Differences and Uncertainties

\begin{tabular}{|c|c|c|c|}
\hline Bulk Enthalpy & RMS (\%) & Maximum (\%) & Minimum (\%) \\
\hline Stand. Earth to Sim. Martian Atm. Difference & 10.7 & 13.2 & 7.0 \\
\hline Standard Earth Atmosphere Uncertainty & 7.6 & 12.0 & 3.2 \\
\hline Simulated Martian Atmosphere Uncertainty & 7.4 & 11.2 & 3.1 \\
\hline
\end{tabular}

\begin{tabular}{|c|c|c|c|}
\hline Fully-Catalytic Cold-Wall Heat Flux & RMS (\%) & Maximum (\%) & Minimum (\%) \\
\hline Stand. Earth to Sim. Martian Atm. Difference & 21.6 & 34.2 & -25.2 \\
\hline Standard Earth Atmosphere Uncertainty & 10.4 & 10 & -10 \\
\hline Simulated Martian Atmosphere Uncertainty & 10.4 & 10 & -10 \\
\hline
\end{tabular}

\begin{tabular}{|c|c|c|c|}
\hline Non-Catalytic Cold-Wall Heat Flux & RMS (\%) & Maximum (\%) & Minimum (\%) \\
\hline Stand. Earth to Sim. Martian Atm. Difference & 33.8 & 64.5 & -26.0 \\
\hline Standard Earth Atmosphere Uncertainty & 10.4 & 10 & -10 \\
\hline Simulated Martian Atmosphere Uncertainty & 10.4 & 10 & -10 \\
\hline
\end{tabular}

\begin{tabular}{|c|c|c|c|}
\hline Stagnation Pressure & RMS (\%) & Maximum (\%) & Minimum (\%) \\
\hline Stand. Earth to Sim. Martian Atm. Difference & 12.7 & 32.4 & -17.9 \\
\hline Standard Earth Atmosphere Uncertainty & 0.21 & 0.63 & 0.08 \\
\hline Simulated Martian Atmosphere Uncertainty & 0.26 & 0.81 & 0.09 \\
\hline
\end{tabular}




\section{B. Comparison of Oxygen-Rich Earth Atmosphere and Simulated Martian Atmosphere}

A representative image of the plasma flow for the oxygen-rich Earth atmosphere is shown in Fig. 22 where the plasma exhibits a similar color to the standard Earth atmosphere even with the extra oxygen. A representative image of the plasma flow for the simulated Martian atmosphere was shown in Fig. 16.

The comparison of the bulk enthalpy for the oxygen-rich Earth and simulated Martian atmospheres in Fig. 23 shows that the Martian bulk enthalpy values are again higher for each of the facility setpoints, with the values for the oxygen-rich Earth atmosphere being 1.8\% higher than those of the standard Earth atmosphere based on the RMS of the percent differences between the two. The arc plasma generator voltage is 3.6\% more for the simulated Martian atmosphere than it is for the oxygen-rich Earth atmosphere based on the RMS of the percent differences between the two. The energy removed by the cooling water from the arc plasma generator is $21.4 \%$ less for the simulated Martian atmosphere than it is for the oxygen-rich Earth atmosphere based on the RMS of the percent differences between the two. The RMS percent difference with the maximum and minimum of the individual setpoint percent differences between the two atmospheres for the bulk enthalpy are presented in Table 7. The RMS percent total uncertainty with the maximum and minimum of the individual setpoint percent total uncertainties in the bulk enthalpy measurement are also presented in Table 7 for each atmosphere. The total uncertainties for the oxygen-rich Earth and standard Earth atmospheres are identical.

Comparisons of the fully-catalytic and non-catalytic heat flux measurements for the oxygen-rich Earth and simulated Martian atmospheres are provided in Figs. 24 and 25, respectively. The heat flux measurement trends for the oxygen-rich Earth atmosphere when compared to the simulated Martian atmosphere are almost identical to those for the standard Earth atmosphere comparison. The oxygen-rich Earth atmosphere fully-catalytic cold-wall heat flux measurements are $6.0 \%$ higher than the standard Earth atmosphere measurements based on the RMS of the percent differences between the two. The oxygen-rich Earth atmosphere non-catalytic cold-wall heat flux measurements are 18.8\% higher than the standard Earth atmosphere measurements based on the RMS of the percent differences between the two. The RMS percent difference with the maximum and minimum of the individual setpoint percent differences between the two atmospheres for the fully-catalytic and non-catalytic heat flux measurements are presented in Table 7. The RMS percent total uncertainty with the maximum and minimum of the individual setpoint percent total uncertainties in these measurements for each atmosphere are also presented in Table 7. A comparison of the percentages of the catalytic energy in the plasma for the oxygen-rich Earth and simulated Martian atmospheres is provided in Fig. 26. The catalytic energy for the oxygen-rich Earth atmosphere compares favorably with that of the simulated Martian atmosphere for each of the facility setpoints. This is in contrast to the same catalytic comparison made between the standard Earth and simulated Martian atmospheres. The reason for this is unknown. However, the result is encouraging when considering the substitution of an oxygen-rich Earth atmosphere for a simulated Martian atmosphere.

A comparison of the stagnation pressures for the oxygen-rich Earth and simulated Martian atmospheres is provided in Fig. 27. The stagnation pressures vary linearly with mass flow rate for the two atmospheres. The stagnation pressure trends for the oxygen-rich Earth atmosphere when compared to the simulated Martian atmosphere are almost identical to those for the standard Earth atmosphere comparison. The oxygen-rich Earth atmosphere stagnation pressures are $7.7 \%$ lower than the standard Earth atmosphere measurements based on the RMS of the percent differences between the two. The RMS percent difference with the maximum and minimum of the individual setpoint percent differences between the two atmospheres for the stagnation pressure are presented in Table 7. The RMS percent total uncertainty with the maximum and minimum of the individual setpoint percent total uncertainties in the stagnation pressure measurement are also presented in Table 7 for each atmosphere. The total uncertainties for the oxygen-rich Earth and standard Earth atmospheres are almost identical. The low total uncertainties for the stagnation pressures and the scale of the y-axis make the error bars appear absent from Fig. 27.

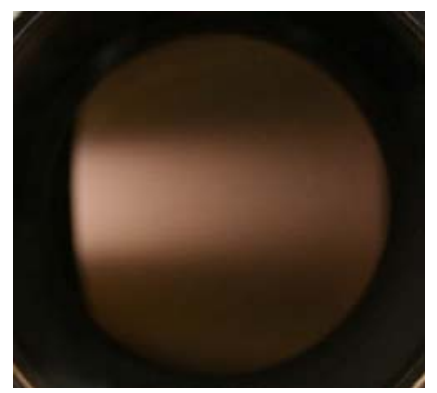

Figure 22. Oxygen-Rich Earth Atmosphere Plasma 


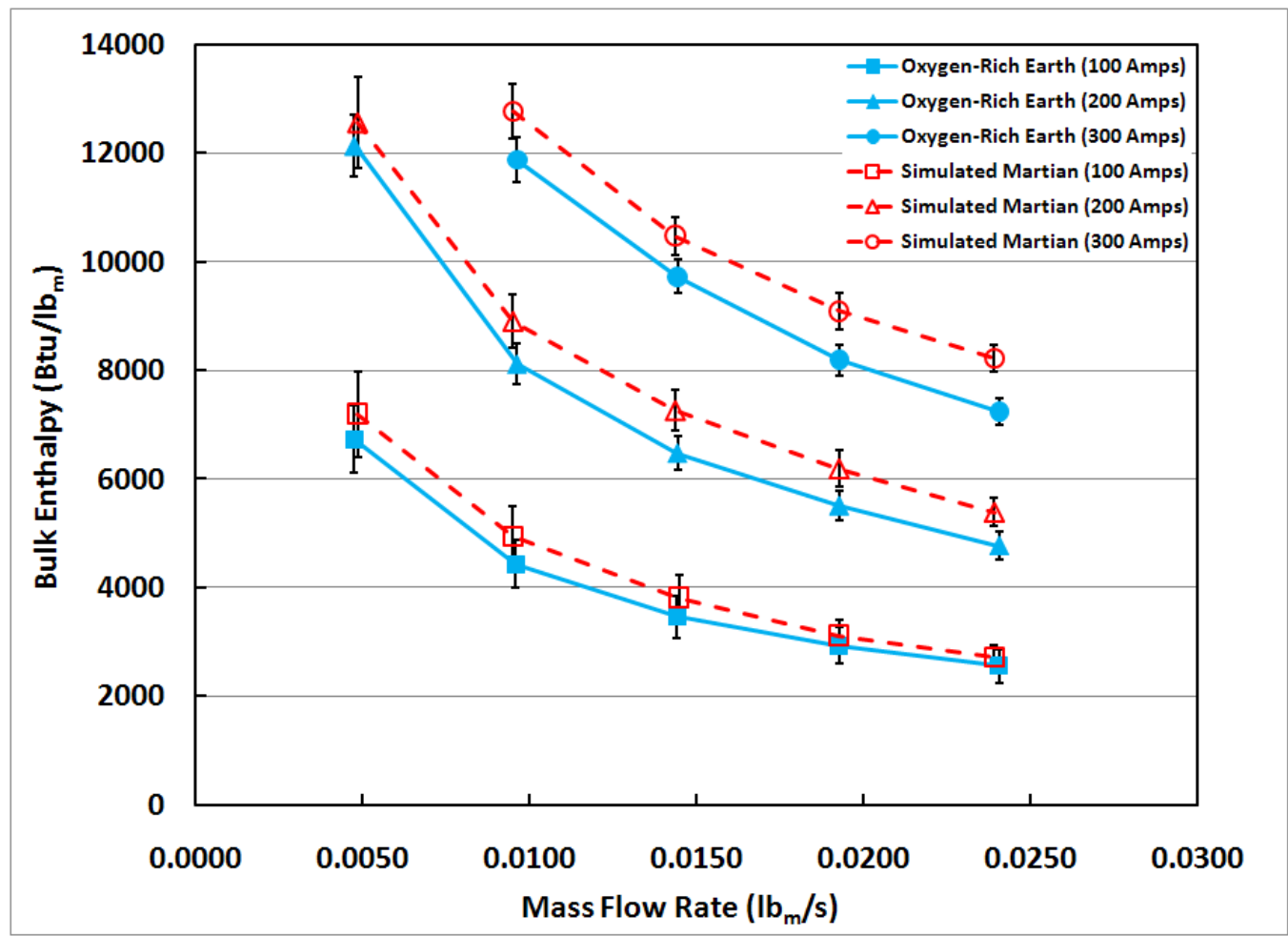

Figure 23. Bulk Enthalpy Comparison

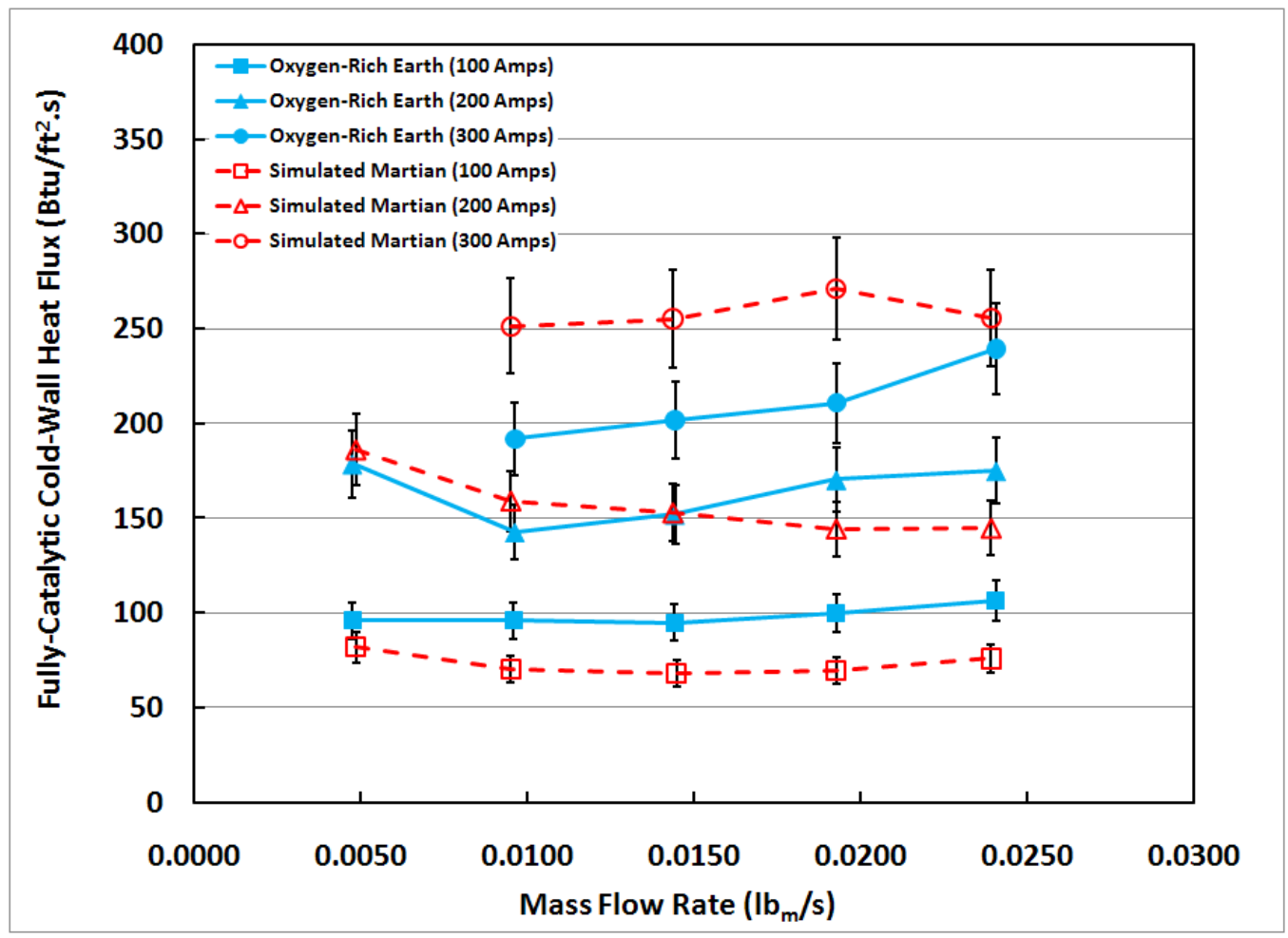

Figure 24. Copper Slug Calorimeter Cold Wall Heat Flux Comparison 


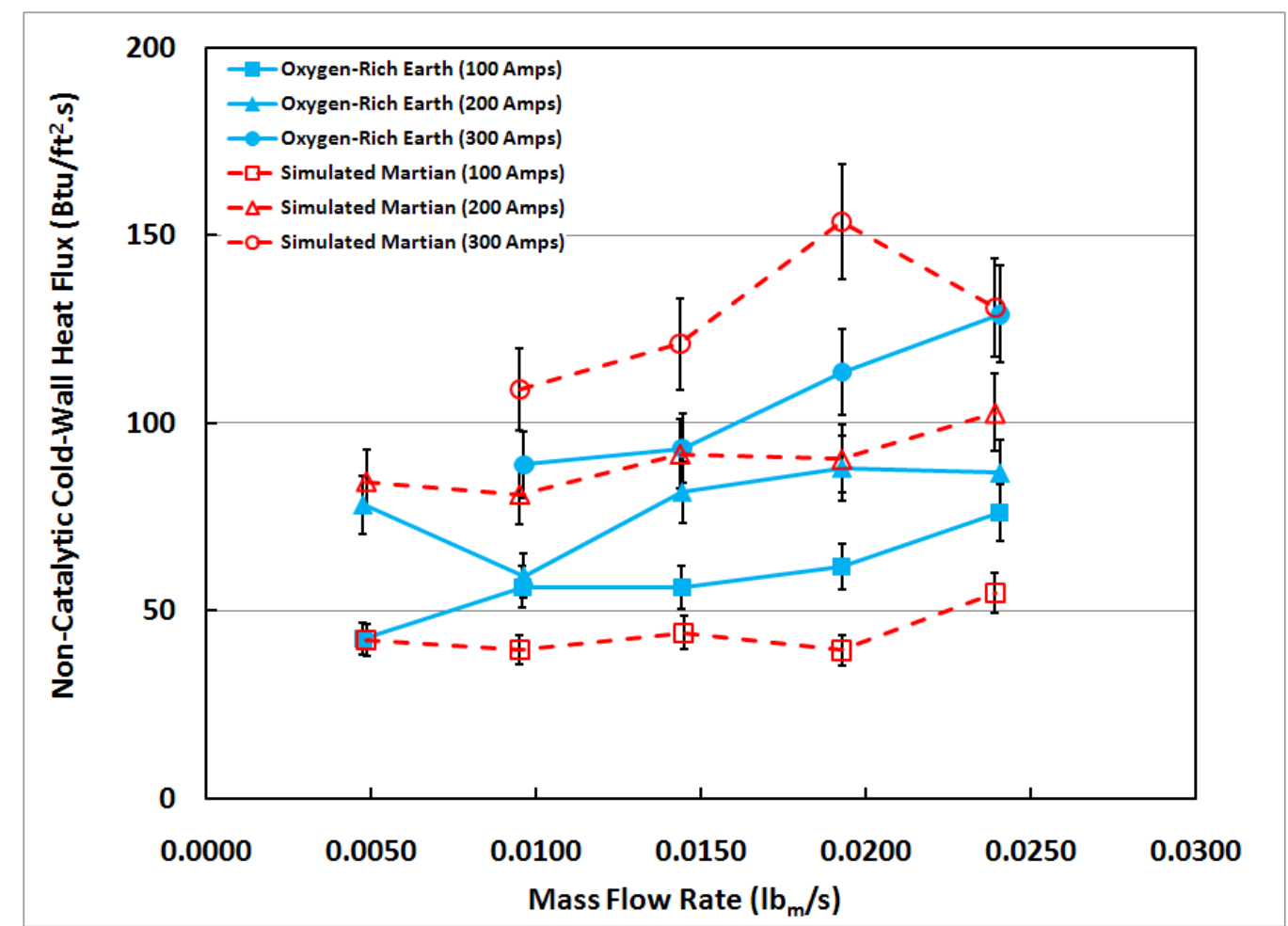

Figure 25. Teflon ${ }^{\circledR}$ Slug Calorimeter Cold Wall Heat Flux Comparison

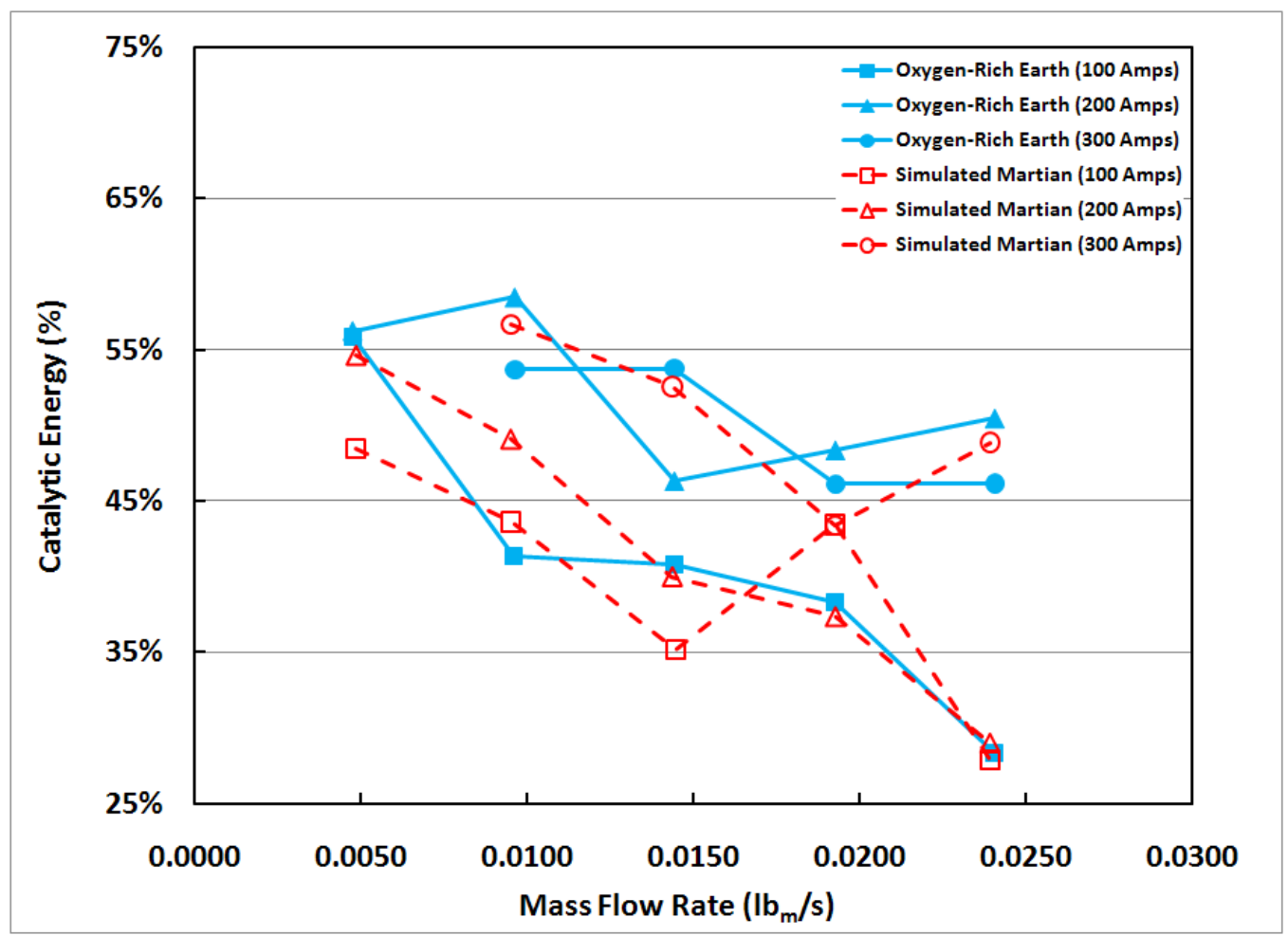

Figure 26. Catalytic Energy in the Plasma Comparison 


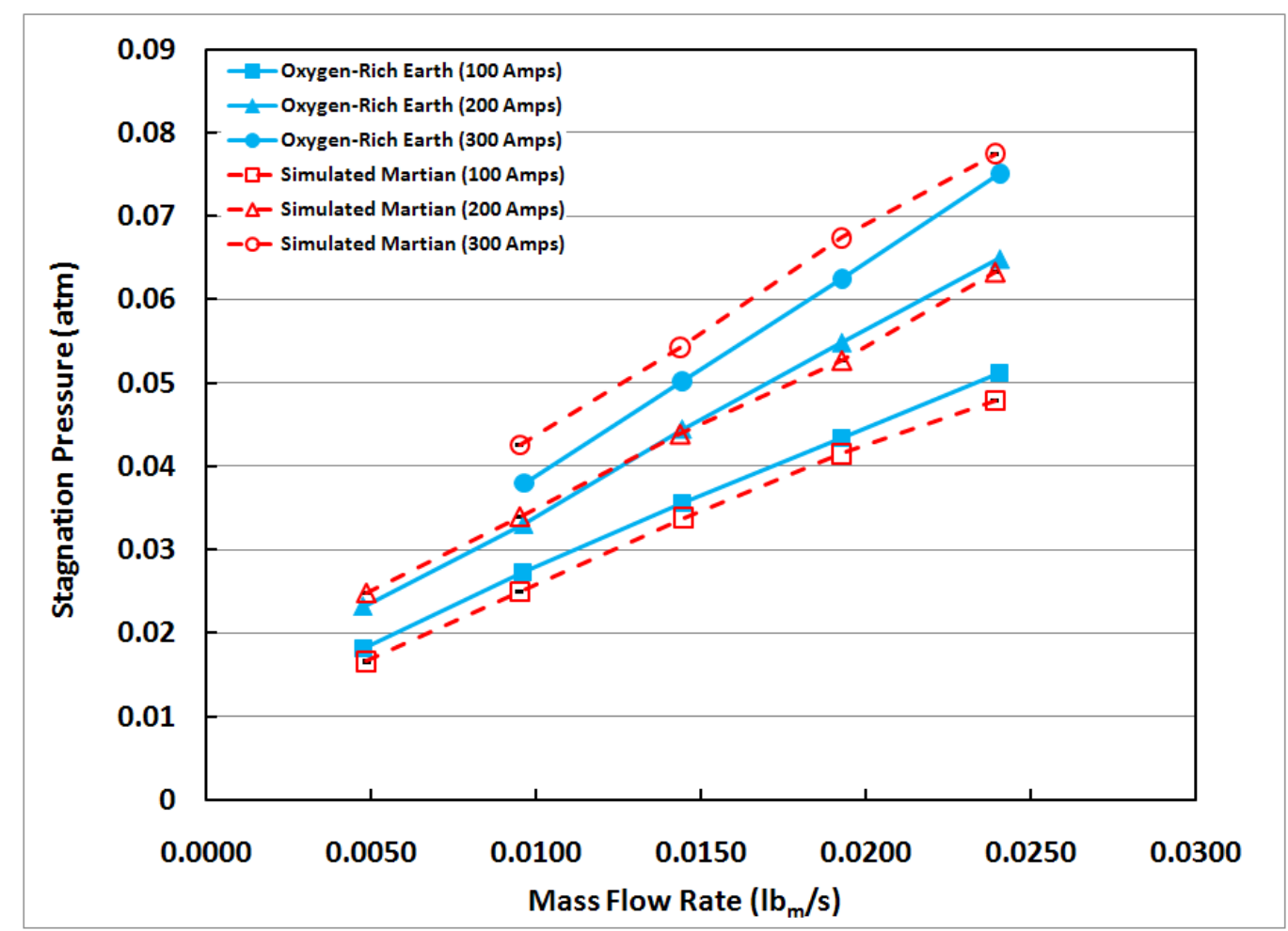

Figure 27. Stagnation Pressure Comparison

Table 7. Oxygen-Rich Earth and Simulated Martian Measurement Differences and Uncertainties

\begin{tabular}{|c|c|c|c|}
\hline Bulk Enthalpy & RMS (\%) & Maximum (\%) & Minimum (\%) \\
\hline Oxy. Earth to Sim. Martian Atm. Difference & 10.2 & 13.5 & 3.4 \\
\hline Oxygen-Rich Earth Atmosphere Uncertainty & 7.6 & 12.0 & 3.2 \\
\hline Simulated Martian Atmosphere Uncertainty & 7.4 & 11.2 & 3.1 \\
\hline
\end{tabular}

\begin{tabular}{|c|c|c|c|}
\hline Fully-Catalytic Cold-Wall Heat Flux & RMS (\%) & Maximum (\%) & Minimum (\%) \\
\hline Oxy. Earth to Sim. Martian Atm. Difference & 22.7 & 31.0 & -30.2 \\
\hline Oxygen-Rich Earth Atmosphere Uncertainty & 10.4 & 10 & -10 \\
\hline Simulated Martian Atmosphere Uncertainty & 10.4 & 10 & -10 \\
\hline
\end{tabular}

\begin{tabular}{|c|c|c|c|}
\hline Non-Catalytic Cold-Wall Heat Flux & RMS (\%) & Maximum (\%) & Minimum (\%) \\
\hline Oxy. Earth to Sim. Martian Atm. Difference & 24.8 & 36.7 & -36.0 \\
\hline Oxygen-Rich Earth Atmosphere Uncertainty & 10.4 & 10 & -10 \\
\hline Simulated Martian Atmosphere Uncertainty & 10.4 & 10 & -10 \\
\hline
\end{tabular}

\begin{tabular}{|c|c|c|c|}
\hline Stagnation Pressure & RMS (\%) & Maximum (\%) & Minimum (\%) \\
\hline Oxy. Earth to Sim. Martian Atm. Difference & 6.7 & 12.2 & -8.5 \\
\hline Oxygen-Rich Earth Atmosphere Uncertainty & 0.21 & 0.64 & 0.08 \\
\hline Simulated Martian Atmosphere Uncertainty & 0.26 & 0.81 & 0.09 \\
\hline
\end{tabular}




\section{Conclusions on Standard Earth, Oxygen-Rich Earth, and Simulated Martian Atmosphere Comparisons}

A direct comparison was made between the standard and oxygen-rich Earth atmospheres and the simulated Martian atmosphere which revealed differences in bulk enthalpies, fully-catalytic and non-catalytic heat fluxes, and stagnation pressures for identical facility setpoints. The simulated Martian atmosphere has higher bulk enthalpies than the standard and oxygen-rich Earth atmospheres. The fully-catalytic and non-catalytic cold-wall heat flux measurements for the simulated Martian atmosphere at the 100 Amp current setpoint are lower than the standard and oxygen-rich Earth atmospheres for each of the mass flow rates. At the 200 Amp current setpoint, the heat flux measurements for the simulated Martian atmosphere are higher than the standard and oxygen-rich Earth atmospheres for the lower mass flow rates, but then become lower than the standard and oxygen-rich Earth atmospheres as the mass flow rates increase. Finally, the heat flux measurements for the simulated Martian atmosphere at the 300 Amp current setpoint are higher than the standard and oxygen-rich Earth atmospheres for each of the mass flow rates. The catalytic energy for the oxygen-rich Earth atmosphere compares favorably with that of the simulated Martian atmosphere for each of the facility setpoints. This is in contrast to the higher catalytic energy found in the standard Earth atmosphere. A trend similar to that found in the heat flux measurement comparisons is present in the stagnation pressures for the standard and oxygen-rich Earth atmospheres when compared to the simulated Martian atmosphere at each of the current setpoints.

The oxygen-rich Earth atmosphere and the simulated Martian atmosphere, while containing the same amount of $\mathrm{O}_{2}$ by weight and being tested at identical facility setpoints, did not have identical results for their bulk enthalpies, fully-catalytic and non-catalytic cold-wall heat flux measurements, and stagnation pressures. The results for the oxygen-rich Earth atmosphere turned out to be a simple offset of the results for the standard Earth atmosphere. This should have been expected as the oxygen-rich Earth atmosphere contains only $4.3 \%$ more oxygen by weight then the standard Earth atmosphere. Regardless of the differences, identical test conditions for the oxygen-rich Earth and simulated Martian atmospheres can still be achieved within the envelope of results presented here by manipulating the facility setpoints. This was the first step in comparing an oxygen-rich Earth atmosphere to a simulated Martian atmosphere for material testing. Based on these results, further research is now possible and recommended to compare material performance (i.e. recession rates, char layers, bond-line temperatures, etc.) in the oxygen-rich Earth and simulated Martian atmospheres.

\section{Comparison to European Facilities}

Test conditions from an experimental study of several European plasma facilities presented in Refs. 36 and 37 were replicated to within 3\% accuracy in HYMETS as shown in Table 8. The fully-catalytic cold-wall heat flux measurements made by the Copper Slug Calorimeter in HYMETS are compared to those made by a Copper Calorimeter Probe in the European facilities L3K, PWK 1 and 2, SIMOUN/COMETE, and the PLASMATRON in Table 9. HYMETS compared favorably to L3K, the only segmented-arc-heated facility in the comparison, at these flow test conditions. The differences between measurements made in HYMETS and L3K were $14 \%$ for FTC I and $6 \%$ for FTC II. Model geometry, facility configuration, facility power level, and flow property differences can easily account for the variation in the measured heat flux values. Both the COMETE and PLASMATRON facilities produce subsonic plasma flows which provide lower heat flux levels when directly compared to the supersonic plasma flows from the segmented-arc-heated facilities. An indirect comparison can be made by normalizing both subsonic and supersonic heat flux values by the method demonstrated in Ref. 37. The normalized comparison establishes that L3K and the PLASMATRON agree to within 3\% of each other for these test conditions ${ }^{37}$, indicating that HYMETS also compares favorably to the PLASMATRON facility by extension. Without normalization, the results for the PWK 1 and 2, and the COMETE facilities do not compare favorably with HYMETS. Normalization of the PWK 1 and 2, and the COMETE facilities was not performed in Ref 37.

Table 8. HYMETS / European Flow Test Conditions (FTC)

\begin{tabular}{|c|c|c|c|}
\hline FTC-I & HYMETS & European & Difference (\%) \\
\hline Stag. Press. (atm) & 0.0355 & 0.0345 & 2.90 \\
\hline Bulk Enth. $\left(\mathrm{Btu} / \mathrm{lb}_{\mathrm{m}}\right.$ ) & 3895 & 3870 & 0.65 \\
\hline
\end{tabular}

\begin{tabular}{|c|c|c|c|}
\hline FTC-II & HYMETS & European & Difference (\%) \\
\hline Stag. Press. (atm) & 0.0349 & 0.0345 & 1.16 \\
\hline Bulk Enth. (Btu/lb $\mathrm{b}_{\mathrm{m}}$ ) & 5596 & 5589 & 0.11 \\
\hline
\end{tabular}


Table 9. Fully-Catalytic Cold-Wall Heat Flux (Btu/ft $\left.{ }^{2} . s\right)$

\begin{tabular}{|c|c|c|c|c|c|}
\hline \multirow{2}{*}{$\begin{array}{c}\text { Test } \\
\text { Conditions }\end{array}$} & \multirow[b]{2}{*}{ HYMETS } & \multicolumn{4}{|c|}{ European Plasma Facilities* } \\
\hline & & L3K & PWK 1 \& 2 & $\begin{array}{l}\text { SIMOUN/ } \\
\text { COMETE }\end{array}$ & PLASMATRON \\
\hline FTC-I & 105 & 92 & --- & --- & 39 \\
\hline FTC-II & 126 & 119 & 202 & 32 & 70 \\
\hline
\end{tabular}

*described in Ref. 36

\section{Summary}

Future robotic and manned missions to Mars with a significant increase in landed mass and a corresponding increase in aerothermodynamic heating will require the recertification of heritage TPS or the certification of new TPS in relevant environments. The test capability to certify TPS in a relevant $\mathrm{CO}_{2}$ environment to simulate Martian entry disappeared in the United States after the early 1970's. To compensate for the lack of testing in $\mathrm{CO}_{2}$, response models were indirectly validated by varying the percentage of oxygen in arc-jet tests. The difference between tests in air and $\mathrm{CO}_{2}$ is the amount of available oxygen, and it is unknown whether an oxygen-rich environment is comparable to a $\mathrm{CO}_{2}$ environment. NASA Langley Research Center's HYMETS facility was recently modified to provide a $\mathrm{CO}_{2}$ test environment. An overview of the modification, operation, and performance of the HYMETS arcjet facility with $\mathrm{CO}_{2}$ as a test gas was provided. A range of test conditions, or envelope map, for the HYMETS facility was performed with a standard and oxygen-rich Earth atmosphere and a simulated Martian atmosphere. Of particular interest is a comparison of results between the oxygen-rich Earth atmosphere and the simulated Martian atmosphere to assess the adequacy of testing in an oxygen-rich Earth atmosphere as a replacement for testing with $\mathrm{CO}_{2}$. Additional tests were performed in HYMETS with test conditions replicating those from an experimental study of several European plasma facilities.

The current operational $\mathrm{CO}_{2}$ gas ratio for HYMETS is $24 \% \mathrm{~N}_{2}, 71 \% \mathrm{CO}_{2}$, and $5 \%$ Ar by volume. This provides a $25 \%$ to $75 \%$ ratio by volume of $\mathrm{N}_{2}$ to $\mathrm{CO}_{2}$ when $\mathrm{Ar}$ is excluded from the mix. This current ratio is closer to achieving the actual gas ratio for the Martian atmosphere of $3 \% \mathrm{~N}_{2}$ to $97 \% \mathrm{CO}_{2}$ than historical attempts. For reference, the operational air ratio for HYMETS is $75 \% \mathrm{~N}_{2}, 20 \% \mathrm{O}_{2}$, and $5 \% \mathrm{Ar}$ by volume. This provides a $79 \%$ to $21 \%$ ratio by volume of $\mathrm{N}_{2}$ to $\mathrm{O}_{2}$ when $\mathrm{Ar}$ is excluded from the mix, which is the actual gas ratio for the Earth atmosphere. Modifications to the facility included a tube and shell heat exchanger with three pressure-regulated stages for the $\mathrm{CO}_{2}$ gas distribution lines, and eight supply cylinders were drawn from simultaneously to prevent the formation of dry-ice during sustained facility operation. Additionally, $\mathrm{CO}_{2}$ introduced a "soot-like" deposit onto the components of the arc plasma generator which decreased the stability of the electric arc and required regular cleaning. A potentially explosive mix of $\mathrm{CO}$ and $\mathrm{O}_{2}$ was produced during operation of the facility with $\mathrm{CO}_{2}$. However, the explosive mix was not combustible below the maximum operating pressure for the facility of 25.4 torr, and the facility was purged with $\mathrm{N}_{2}$ and $\mathrm{Ar}$ before and after operation with $\mathrm{CO}_{2}$. The production of particulate $\mathrm{CN}$ or HCN during facility operation with $\mathrm{CO}_{2}$ and $\mathrm{N}_{2}$ was determined to be negligible. The production of NO during facility operation with $\mathrm{CO}_{2}$ and $\mathrm{N}_{2}$ was confirmed by RGA measurements and NO PLIF measurements, however, the amounts were within the existing limits for the HYMETS air permit. Higher ratios of $\mathrm{CO}_{2}$ to $\mathrm{N}_{2}$ than the current ratio, $75 \% \mathrm{CO}_{2}$ to $25 \% \mathrm{~N}_{2}$ by volume, resulted in unacceptable oxidation of the cathode. A possible method for future work in achieving higher ratios is to introduce CO near the cathode to reduce the amount of $\mathrm{N}_{2}$ needed to shield the cathode. The tungsten button in the cathode is not easily oxidized by CO.

A direct comparison was made between the standard and oxygen-rich Earth atmospheres and the simulated Martian atmosphere which revealed differences in bulk enthalpies, fully-catalytic and non-catalytic heat fluxes, and stagnation pressures for identical facility setpoints. The simulated Martian atmosphere has higher bulk enthalpies than the standard and oxygen-rich Earth atmospheres. The fully-catalytic and non-catalytic cold-wall heat flux measurements for the simulated Martian atmosphere at the 100 Amp current setpoint are lower than the standard and oxygen-rich Earth atmospheres for each of the mass flow rates. At the $200 \mathrm{Amp}$ current setpoint, the heat flux measurements for the simulated Martian atmosphere are higher than the standard and oxygen-rich Earth atmospheres for the lower mass flow rates, but then become lower than the standard and oxygen-rich Earth atmospheres as the mass flow rates increase. Finally, the heat flux measurements for the simulated Martian atmosphere at the 300 Amp current setpoint are higher than the standard and oxygen-rich Earth atmospheres for each of the mass flow rates. The catalytic energy for the oxygen-rich Earth atmosphere compares favorably with that of the simulated Martian atmosphere for each of the facility setpoints. This is in contrast to the higher catalytic 
energy found in the standard Earth atmosphere. A trend similar to that found in the heat flux measurement comparisons is present in the stagnation pressures for the standard and oxygen-rich Earth atmospheres when compared to the simulated Martian atmosphere at each of the current setpoints.

The oxygen-rich Earth atmosphere and the simulated Martian atmosphere, while containing the same amount of $\mathrm{O}_{2}$ by weight and being tested at identical facility setpoints, did not have identical results for their bulk enthalpies, fully-catalytic and non-catalytic cold-wall heat flux measurements, and stagnation pressures. The results for the oxygen-rich Earth atmosphere turned out to be a simple offset of the results for the standard Earth atmosphere. This should have been expected as the oxygen-rich Earth atmosphere contains only $4.3 \%$ more oxygen by weight then the standard Earth atmosphere. Regardless of the differences, identical test conditions for the oxygen-rich Earth and simulated Martian atmospheres can still be achieved within the envelope of results presented here by manipulating the facility setpoints. This was the first step in comparing an oxygen-rich Earth atmosphere to a simulated Martian atmosphere for material testing. Based on these results, further research is now possible and recommended to compare material performance (i.e. recession rates, char layers, bond-line temperatures, etc.) in the oxygen-rich Earth and simulated Martian atmospheres.

Finally, two different test conditions from an experimental study of several European plasma facilities were replicated to within 3\% accuracy. HYMETS compared favorably to European plasma facility L3K, the only segmented arc heated facility in the comparison, with differences in fully-catalytic cold-wall heat flux of $14 \%$ and $6 \%$ for the two test conditions. A normalized comparison established that L3K and the PLASMATRON, another European plasma facility, agreed to within 3\% of each other for these test conditions, indicating that HYMETS also compared favorably to the PLASMATRON facility by extension.

\section{Acknowledgments}

The authors would like to acknowledge the support of the Hypersonics project under NASA's Fundamental Aeronautics Program, and in particular James Pittman, F. McNeil Cheatwood, and Anthony M. Calomino, for providing the resources to upgrade the HYMETS facility. The authors would also like to thank the following people for their contribution in making this series of tests a success:

- David N. Brewer, H. Kevin Rivers, Walter E. Bruce, Kamran Daryabeigi, and Rufus Sykes, NASA Langley Research Center

- George C. Raiche, NASA Ames Research Center

- Brian C. Shafer, Jacobs Technology, NASA Johnson Space Center

- J. Michael Lester, PEC Professional Services, Manchester, TN 37355

\section{References}

\footnotetext{
${ }^{1}$ Struass, E., "New Ablative Heat Shield Materials for Mars Landers," Society of Automotive Engineers, Aeronautic and Space Engineering and Manufacturing Meeting, SAE No. 660654, Los Angeles, California, October 1966.

${ }^{2}$ Struass, E., "Superlight Ablative Systems for Mars Lander Thermal Protection,” Journal of Spacecraft and Rockets, Vol. 4, No. 10, pp. 1304-1309, 1967.

${ }^{3}$ Strauss, E., "Response of Superlight Ablators to Various Heat Pulses,” AIAA-1968-301, April 1968.

${ }^{4}$ Congdon, W., Edquist, C., and Henline, W., “Thermal Protection Studies for the 1996 Pathfinder Mission to Mars,” AIAA1994-249, January 1994.

${ }^{5}$ Willcockson, W., "Mars Pathfinder Heat Shield Design and Flight Experience,” Journal of Spacecraft and Rockets, Vol. 36, No. 33, pp. 374-379, May-June 1999.

${ }^{6}$ Beck, R., Driver, D., Wright, M., Laub, B., Hwang, H., Slimko, E., Edquist, K., Sepka, S., Willcockson, W., and Thames, T., "Development of the Mars Science Laboratory Heatshield Thermal Protection System,” AIAA-2009-4229, June 2009.

${ }^{7}$ Wright, M., Beck, R., Edquist, K., Driver, D., Sepka, S., Slimko, E., Willcockson, W., DeCaro, A., and Hwang, H., “Sizing and Margins Assessment of the Mars Science Laboratory Aeroshell Thermal Protection System,” AIAA-2009-4231, June 2009.

${ }^{8}$ Gülhan, A., Esser, B., Koch, U., and Hannemann, K., "Mars Entry Simulation in the Arc Heated Facility L2K," Proceedings of the 4th European Symposium on Aerothermodynamics for Space Applications, Capua, Italy, October 15-18, 2001

${ }^{9}$ Herdrich, G., Auweter-Kurtz, M., Endlich, P., and Laux, T., "Simulation of Atmospheric Entry Maneuvers Using the Inductively Heated Plasma Wind Tunnel PWK3,” AIAA-2003-3637, June 2003.

${ }^{10}$ Labaste, V., and Mignot, Y., "EADS Launch Vehicles Main Achievements for Planetary Exploration Missions,” Proceedings of the 4th European Workshop: Hot Structures and Thermal Protection Systems for Space Vehicles, Palermo, Italy, November 26-29, 2002.
} 
${ }^{11}$ Vancrayenest, B., Playez, M., Duchêne, L., and Fletcher, D., "Emission Spectroscopic Measurements in a CO2 Plasma,” 3rd International Symposium Atmospheric Reentry Vehicles and Systems, Arcachon, France, March 24-27, 2003. (MP60)

${ }^{12}$ Kolesnikov, A., Yakushin, M., Pershin, I., Vasil'evskii, S., Bykova, N.G., Gordeev, A.N., Chazot, O., and Muylaert, J., "Comparative Analysis of the Inductive Plasmatrons Capabilities for Thermochemical Simulation at the Earth and Mars Atmospheric Entry Conditions," 11th International Conference on Methods for Aerophysical Research, ICMAR 2002, Novosibirsk, Russia, July 1-5, 2002.

${ }^{13}$ Kitagawa, K., Goto, H., Yasuhara, M., Kobayashi, Y., and Sakai, T., "Emission Spectra Measurements in the Arc Heated Flow of Huels Type Arc Heater,” AIAA-2008-2507, May 2008.

${ }^{14}$ Wiedemann, K., Clark, R., and Sankaran, S., “Emittance, Catalysis, and Dynamic Oxidation of Ti-14AL-21Nb,” NASA TP-2955, November 1989.

${ }^{15}$ Glass, D., “Oxidation and Emittance Studies of Coated Mo-Re,” NASA CR-201753, October 1997.

${ }^{16}$ Bird, R., Wallace, T., and Sankaran, S., "Development of Protective Coatings for High-Temperature Metallic Materials,” Journal of Spacecraft and Rockets, Vol. 41, No. 2, pp. 213-220, March-April 2004.

${ }^{17}$ Cunningham, J., “Commissioning Plan for the HYMETS Power Supply,” Ares Corporation, Tullahoma, TN 37388, February 2006.

${ }^{18}$ LabVIEW $^{\mathrm{TM}}$ Software, Version 8.5, National Instruments Corporation, Austin, Texas, 2007. Trade names and trademarks used in this report are for identification only. Their usage does not constitute an official endorsement, either expressed or implied, by the National Aeronautics and Space Administration.

${ }^{19}$ Scott, C., "Survey of Measurements of Flow Properties in Arcjets," Journal of Thermophysics and Heat Transfer, Vol. 7, No. 1, pp. 9-24, January-March 1993.

${ }^{20}$ Gülhan, A., and Esser, B., “A Study on Heat Flux Measurements in High Enthalpy Flows,” AIAA-2001-3011, June 2001.

${ }^{21}$ ASTM Standard E 511, "Standard Test Method for Measuring Heat Flux Using a Copper-Constantan Circular Foil, HeatFlux Transducer,” Copyright ASTM International, 100 Barr Harbor Drive, PO Box C700, West Conshohocken, PA 19428-2959, United States.

${ }^{22}$ ASTM Standard E 457, "Standard Test Method for Measuring Heat-Transfer Rate Using a Thermal Capacitance (Slug) Calorimeter,” Copyright ASTM International, 100 Barr Harbor Drive, PO Box C700, West Conshohocken, PA 19428-2959, United States.

${ }^{23}$ Nawaz, A., and Santos, J., "Assessing Calorimeter Evaluation Methods in Convective and Radiative Heat Flux Environment,” AIAA-2010-4905, June 2010.

${ }^{24}$ Hiester, N, and Clark, C., "Feasibility of Standard Evaluation Procedures for Ablating Materials," NASA CR-379, February 1966.

${ }^{25}$ Hiester, N, and Clark, C., “Comparative Evaluation of Ablating Materials in Arc Plasma Jets,” NASA CR-1207, December 1968.

${ }^{26}$ ASTM Standard E 341, “Standard Practice for Measuring Plasma Arc Gas Enthalpy by Energy Balance,” Copyright ASTM International, 100 Barr Harbor Drive, PO Box C700, West Conshohocken, PA 19428-2959, United States.

${ }^{27}$ Miller, P. A., “Exhaust-Gas Measurements from NASA's HYMETS Arc-Jet,” Sandia National Laboratories Report SAND2010-XXXX, Albuquerque, New Mexico and Livermore, California, November 2010.

${ }^{28}$ Davletshina, T.A., and Cheremisinoff, N.P., Fire and Explosion Hazards Handbook of Industrial Chemicals, William Andrew Publishing/Noyes, New Jersey, 1998.

${ }^{29}$ Crowl, D. A., Understanding Explosions, Center for Chemical Process Safety/AIChE, New York, 2003

${ }^{30}$ Johnston, R., Cyanide Sampling and Analysis, HYMETS, Building 1148, SQA2, April 2010.

${ }^{31}$ Universal Laboratories Report of Analysis Order ID 1001521, January 2010.

${ }^{32}$ Inman, J., Bathel, B., Johansen, C., Danehy, P., Jones, S., Gragg, J., Splinter, S., "Nitric Oxide PLIF Measurements in the Hypersonic Materials Environmental Test System (HYMETS)," to be presented the 49th AIAA Aerospace Sciences Meeting Including The New Horizons Forum and Aerospace Exposition, Orlando, FL, 4-7 January 2011.

${ }^{33}$ Commonwealth of Virginia, Department of Environmental Quality Permit Registration No.: 60051, Permit AFS ID No.: 51-650-00006, Operating Limit: No more than 525 hours per year, Emissions Limit: 2.6 tons NO $\mathrm{NO}_{2}$ per year, December 2007.

${ }^{34}$ Sabourin, J., and Yetter, R., "High-Temperature Heterogeneous Reaction Kinetics of Tungsten Oxidation by $\mathrm{CO}_{2}$, CO, and $\mathrm{O}_{2}$,” Journal of Propulsion and Power, Vol. 25, No. 2, pp. 490-498, March-April 2009.

${ }^{35}$ Lester, J. M., "Summary of Analysis of the Simulation of Martian Atmospheres in the Hypersonic Materials and Environmental Test System (HyMETS),” PEC Document No. 06-2108-07-01, Copyright PEC Professional Services, 1007 Keylon Street, Manchester, Tennessee 37355, April 2007.

${ }^{36}$ Gülhan, A., Esser, B., Del Vecchio, A., Löhle, S., Sauvage, N., Chazot, O., and Asma, C., “Comparative Heat Flux Measurements on Standard Models in Plasma Facilities,” AIAA-2005-3324, May 2005.

${ }^{37}$ Fletcher, D., and Playez, M., “Characterization of Supersonic and Subsonic Plasma Flows,” AIAA-2006-3294, June 2006. 